\title{
Recent advances in asymmetric Strecker reactions
}

\author{
Xiao-Hua Cai* and Bing Xie \\ College of Chemistry and Environmental Science, Guizhou Minzin University, \\ Guiyang 550 025, P. R. China \\ E-mail: caixh1111@163.com
}

DOI: http://dx.doi.org/10.3998/ark.5550190.p008.487

\begin{abstract}
The Strecker reaction is one of the most attractive methods for the synthesis of $\alpha$-amino acids and other bioactive compounds including natural products. The asymmetric Strecker reaction represents a simple and efficient method for the synthesis of optically pure $\alpha$-amino acid derivatives, nucleic acids, various nitrogen and sulfur containing heterocycles and pharmaceuticals. Over the past several decades, considerable effort has been devoted towards the development of asymmetric Strecker reactions. This review provides an overview of recent asymmetric Strecker reactions, from diastereoselective reactions and catalytic enantioselective reactions including chiral catalytic metal systems and chiral organocatalytic systems.
\end{abstract}

Keywords: Asymmetric Strecker reaction; $\alpha$-amino acids; enantioselective; chiral metal complex catalysts; chiral organocatalysts

\section{Table of Contents}

1. Introduction

2. Diastereoselective Strecker Reactions

2.1. $\alpha$-Phenylglycinol as the chiral auxiliary

2.2. Induction by chiral nonracemic ketimines or imines

3. Enantioselective Strecker Reaction Using Metal Catalysts

3.1. Using chiral aluminum(III) complexes

3.2. Using chiral titanium(IV) complexes

3.3. Using chiral lanthanide(III) complexes

3.4. Using chiral vanadium(V) complexes

3.5. Using chiral ruthenium(II) complexes

3.6. Using chiral magnesium(II) complexes

4. Enantioselective Strecker Reactions Using Organocatalysts 
4.1. Cinchona alkaloid-catalyzed reactions

4.2. Phase-transfer-catalyzed reactions

4.3. Reactions catalysed by urea and thiourea derivatives

4.3.1. Urea derivatives

4.3.2. Thiourea derivatives

4.4. Reactions catalysed by chiral bisformamides

4.5. Reactions catalysed by chiral BINOL-phosphoric acids

4

.6. Reactions catalysed by chiral dicarboxylic acids

\section{Introduction}

The Strecker reaction, ${ }^{1}$ the oldest known synthesis of $\alpha$-aminonitriles, is one of the most general methods, potentially useful for the syntheses of $\alpha$-amino acids and other bioactive compounds including natural products. In addition, the Strecker reaction represents one of the simplest and most economical methods for the preparation of $\alpha$-amino acids on both laboratory and industrial scale. ${ }^{2}$ The classic variant of this reaction represents the condensation of aldehydes or ketones with primary or secondary amines (even with $\mathrm{NH}_{3}$ ) to give imines (Schiff bases). The imines then react with $\mathrm{CN}^{-}$anion (from $\mathrm{KCN}$ or $\mathrm{HCN}$ ) to give $\alpha$-aminonitriles, which are subsequently hydrolyzed to the desired $\alpha$-amino acid (Scheme 1). Unfortunately, the original Strecker synthesis can only produce a racemic mixture of the enantiomeric forms of an amino acid. For this reason, many chemists have taken an interest in the development of enantioselective, or catalytic asymmetric, reactions that use a catalyst to selectively increase the formation of a particular enantiomer.

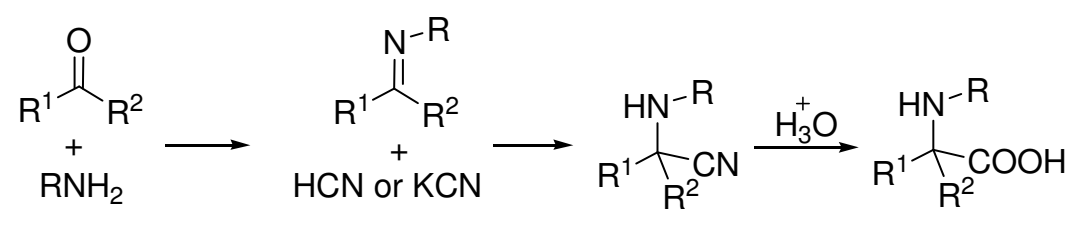

$\mathrm{R}^{1}=\mathrm{Ar}$, alkyl; R, $\mathrm{R}^{2}=\mathrm{Ar}$, alkyl, $\mathrm{H}$

\section{Scheme 1}

In general, two approaches have been used to achieve successful asymmetric Strecker reactions and obtain optically active $\alpha$-amino nitriles. The first is the addition of cyanide to chiral non-racemic imines, and the second is the enantioselective catalytic cyanation of achiral imines. Although asymmetric Strecker reactions using chiral aldehyde or ketone derived imines can be found in many natural product syntheses, this strategy tends to be extremely specific and highly structure-dependent. To carry out a reaction of this strategic type requires stoichiometric 
amounts of a chiral auxiliary. After the reaction, the auxiliary group must be cleaved from the product, and the chiral auxiliaries recovered and reused. The catalytic asymmetric Strecker reaction $^{3-9}$ has proved to be a simple and efficient method for the synthesis of optically pure $\alpha$ amino acid derivatives. ${ }^{10}$ Its development has been extremely fast since the first report of such a reaction appeared in 1996. ${ }^{11}$ Therefore, the development of catalytic enantioselective Strecker reactions has been the focus of increasing attention in the field of asymmetric synthesis. Over the past several decades, great strides have been made in the asymmetric hydrocyanation of imines, in particular, in the field of catalytic asymmetric Strecker reactions. Some highly efficient asymmetric methods with excellent enantioselectivities, low catalyst loading and new cyanide sources used are also developed. The following review will summarize recent achievements in asymmetric Strecker reaction from diastereoselective reactions and catalytic enantioselective reactions including chiral catalytic metal systems and chiral organocatalytic systems.

\section{Diastereoselective Strecker Reactions}

Diastereoselective Strecker reactions featuring chiral nonracemic imines and analogues as substrates are important strategies for preparing $\alpha$-aminonitriles, $\alpha$-amino acids and their derivatives. The use of chiral optically pure amines as the chiral auxiliary for achieving the highly diastereoselective Strecker reaction has evolved into a relatively general and robust approach for accessing various enantiomerically pure $\alpha$-amino acids. ${ }^{12-18}$ The first example of a diastereoselective Strecker reaction assisted by a chiral auxiliary on the amine component was reported by Harada, who used $(S)$-1-phenylethylamine as the chiral auxiliary to obtain chiral $(S)$ $\alpha$-amino acids after acid hydrolysis of the nitrile and cleavage and recovery of the $N$-alkyl group. ${ }^{19,20}$ Later, some examples in which excellent chiral induction effects have been observed in diastereoselective Strecker reactions. ${ }^{21-30}$

\section{1. $\alpha$-Phenylglycinol as the chiral auxiliary}

In 2008, Liu and coworkers synthesized $\beta, \beta$-difluoro amino acids from commercially available

ethyl bromodifluoroacetate using cross-coupling and Strecker reactions as key steps. ${ }^{31}$ The coupling reaction of aryl iodides with ethyl bromodifluoroacetate gave the corresponding coupling products, which were transformed to 2-difluoromethyl-1,3-oxazolidines $\mathbf{1}$ in two steps. Boron trifluoride etherate promoted Strecker reaction of 2-difluoromethyl-1,3-oxazolidines gave $\alpha$-aminonitriles $\mathbf{2}$ and $\mathbf{3}$ in good yields and diastereoselectivities (Scheme 2). After removal of chiral auxiliary and hydrolysis of the nitrile group, $\beta, \beta$-difluoro phenylalanine 4 was obtained with $73 \%$ ee (Scheme 3). It was noteworthy that partial racemization occurred during the hydrolysis of nitrile group. 


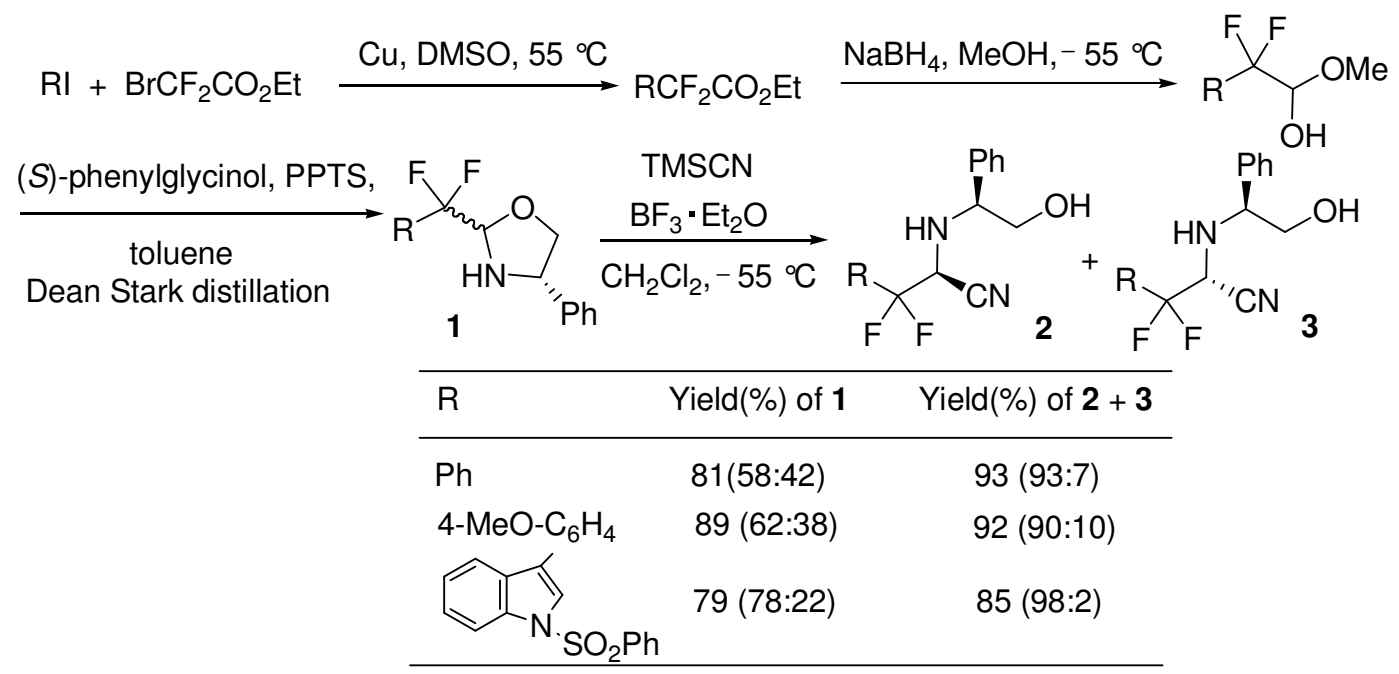

\section{Scheme 2}

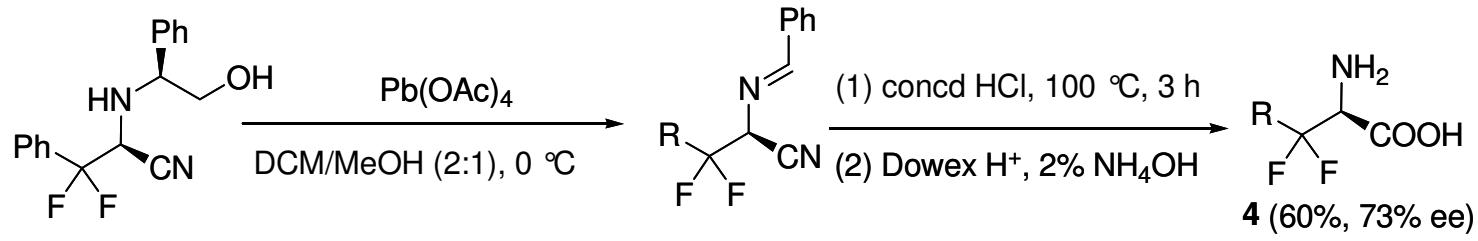

\section{Scheme 3}

In 2011, Brigaud and coworkers ${ }^{32}$ reported a concise synthesis of enantiopure $(S)$ - and $(R)$ $\alpha$-Tfm-aspartic acid (Scheme 4) and $\alpha$-Tfm-serine (Scheme 5). The key step in the reaction involved a Strecker-type reaction on chiral $\mathrm{CF}_{3}$-oxazolidines (Fox) derived from ethyl 4,4,4trifluoroacetoacetate (ETFAA) or ethyl trifluoropyruvate. The following year, Barnwell et al. developed a diastereoselective Strecker reaction using $(R)-(-)$-phenylglycinol formed the basis of a concise scalemic route to dialkylhydantoin 5 (Scheme 6$){ }^{33}$ The phenylglycinol functionality was exploited in the manipulation of the aminonitrile Strecker product through to the dialkylhydantoin via a short, efficient sequence involving crystalline intermediates.

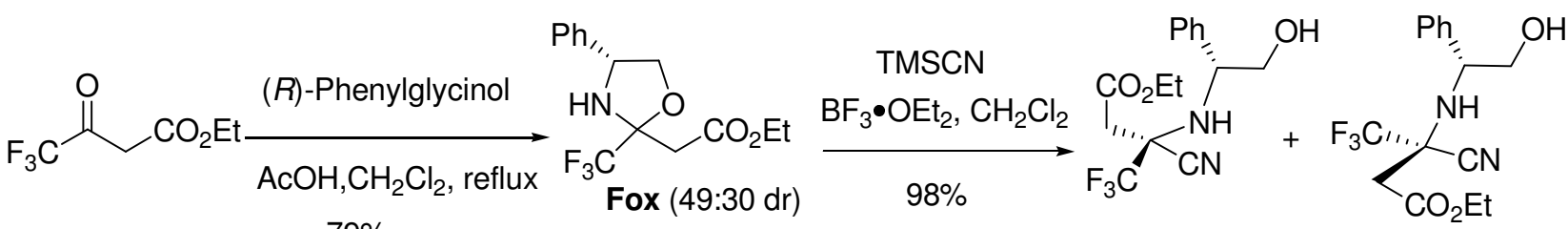
$79 \%$

$(S):(R)=55: 45$

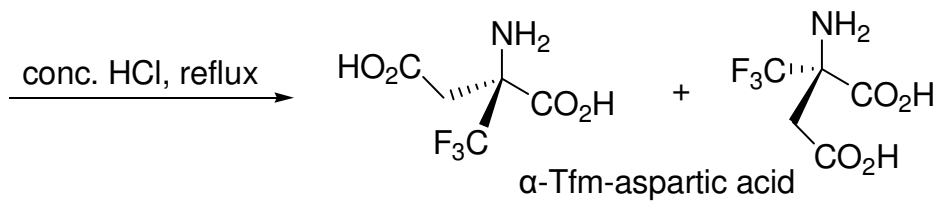

\section{Scheme 4}




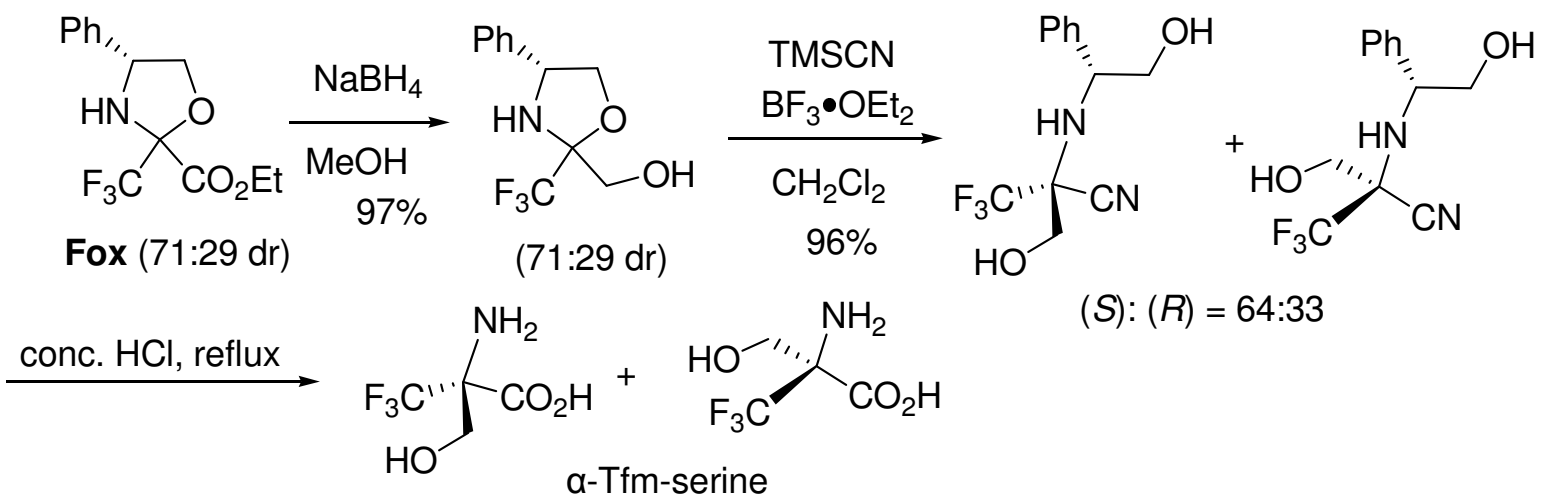

\section{Scheme 5}
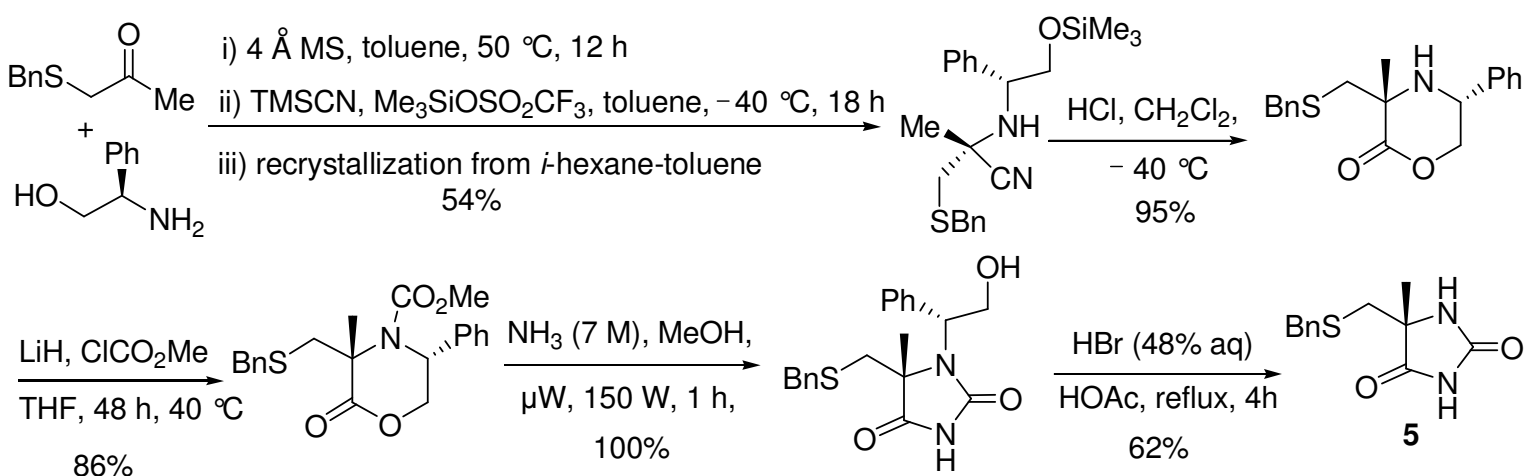

\section{Scheme 6}

\subsection{Induction by chiral nonracemic ketimines or imines}

In 2012, Yuan et al. achieved a solvent-controlled, highly stereoselective, asymmetric Strecker reaction of trifluoromethyl $\alpha, \beta$-unsaturated $N$-tert-butylsulfinyl ketimines with TMSCN. ${ }^{34}$ The diastereomers of $\alpha$-trifluoromethyl unsaturated cyano amines were obtained, respectively, in good yields with excellent diastereoselectivities in terms of the different solvents used (Scheme $7)$. In cyclohexane, the $(S, R s)$-isomer was obtained with up to $17: 1$ d.r., whereas the $(R, R s)$ isomer was generated as the main product with up to $145: 1$ d.r. in DMF at $-60{ }^{\circ} \mathrm{C}$. This study would provide an efficient method for the preparation of novel $\alpha, \beta$-unsaturated $\alpha$ trifluoromethylated amine derivatives of biological interest. 


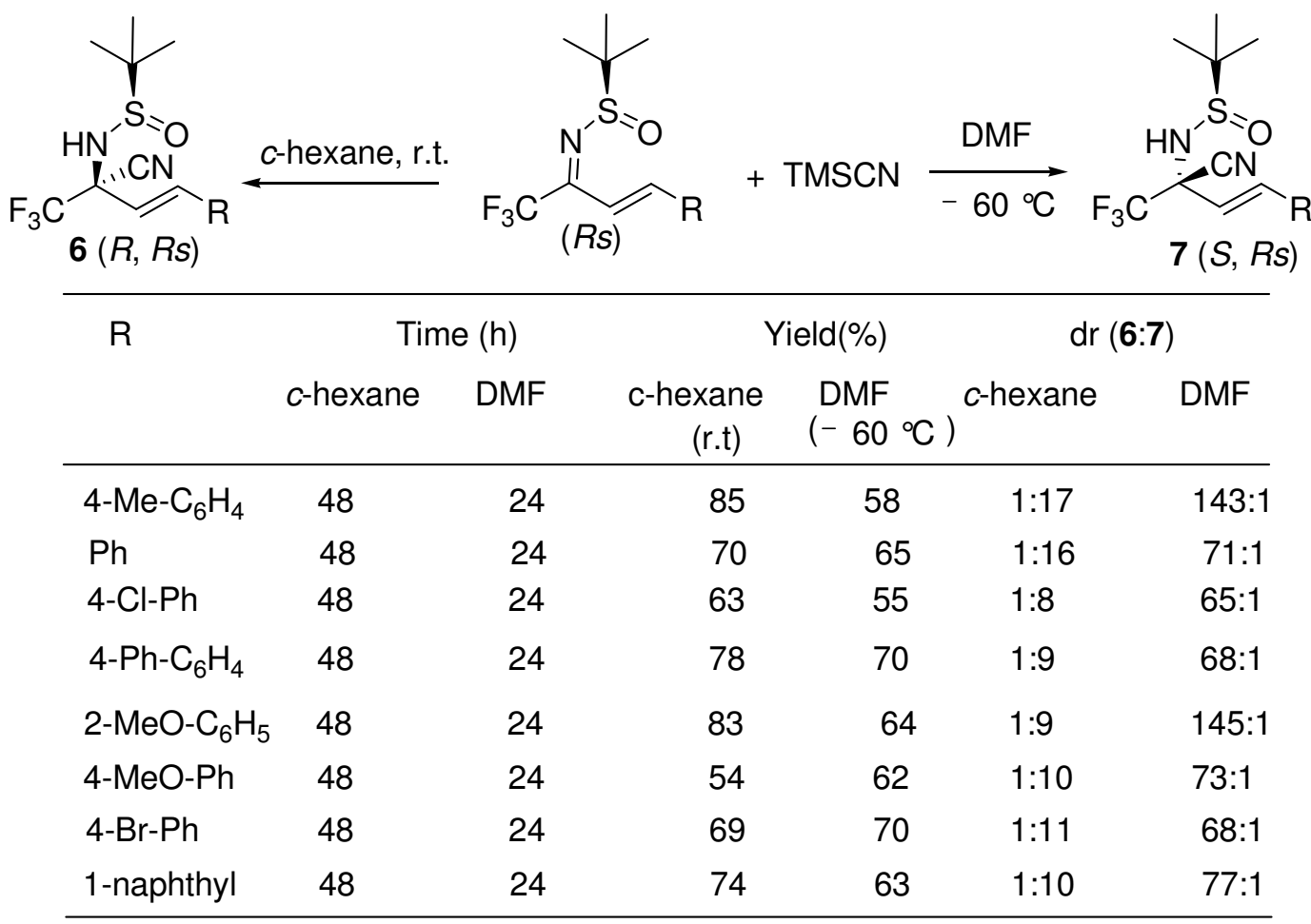

\section{Scheme 7}

In 2013, Ewas and coworkers successfully synthesized constrained L-AP4 analogues, (2S,1'R,2'S)- and (2S,1'S,2'R)-2-(2'-phosphonocyclopropyl) glycines as well as their phenyl analogues (2S,1'S,2'R,3'S)-2-(2'-phosphono-3'-phenylcyclopropyl) glycine (PPCG-1) and $\left(2 \mathrm{~S}, 1^{\prime} \mathrm{R}, 2^{\prime} \mathrm{S}, 3^{\prime} \mathrm{R}\right)$-2-(2'-phosphono-3'-phenylcyclopropyl) glycine (PPCG-2). ${ }^{35}$ The stereogenic centers in cyclopropane ring were formed under sulfinyl group control, in asymmetric cyclopropanation of enantiomerically pure $\alpha$-phosphoryl vinyl sulfoxides (Scheme 8). The sulfinimine-mediated asymmetric Strecker reaction allowed introduction of the amino acid moiety.

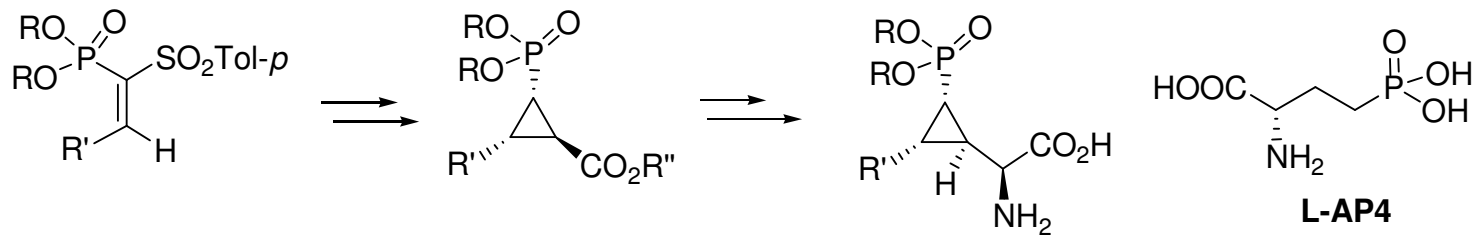

\section{Scheme 8}

Pori et al. developed the synthesis of a series of new chiral $\alpha$-aminonitriles in a diastereoselective Strecker reaction in a one-pot procedure with aldehydes, enantiopure amines, and acetone cyanohydrin in water. ${ }^{36}$ Primary and secondary amines derived from $L$ - $\alpha$-amino 
acids were used as sources of chirality, and the reactions proceeded efficiently without any catalyst at room temperature (Scheme 9). The chemical transformation of proline-derived chiral $\alpha$-amino-nitriles into chiral amino-diacids, aminols, and amides was also reported (Scheme 10).

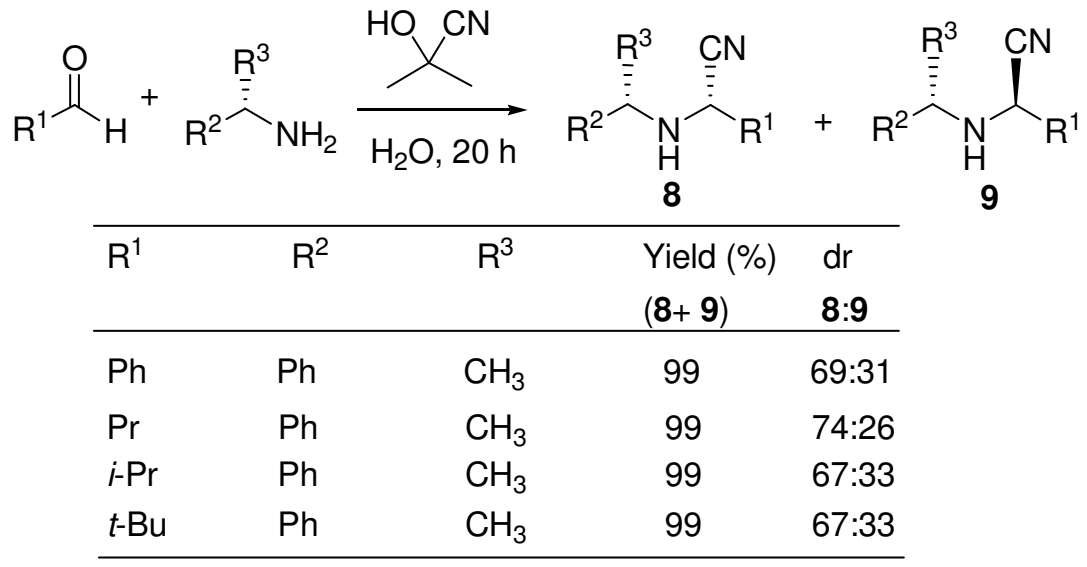

\section{Scheme 9}

\begin{tabular}{|c|c|c|c|c|c|c|c|c|c|}
\hline $\mathrm{R}^{1}$ & $\mathrm{R}^{2}$ & $\mathrm{R}^{3}$ & $\begin{array}{l}\text { Yield (\%) } \\
10+11\end{array}$ & $\begin{array}{c}d r \\
10: 11\end{array}$ & $\mathrm{R}^{1}$ & $\mathrm{R}^{2}$ & $\mathrm{R}^{3}$ & $\begin{array}{l}\text { Yield (\%) } \\
10+11\end{array}$ & $\begin{array}{c}d r \\
10: 11\end{array}$ \\
\hline $\mathrm{Ph}$ & $\mathrm{Ph}$ & $\mathrm{OH}$ & 85 & $81: 19$ & $\operatorname{Pr}$ & $\mathrm{PhCH}_{2}$ & $\mathrm{CO}_{2} \mathrm{Me}$ & 25 & 63:37 \\
\hline $\operatorname{Pr}$ & $\mathrm{Ph}$ & $\mathrm{OH}$ & 99 & $80: 20$ & $i-\operatorname{Pr}$ & $\mathrm{PhCH}_{2}$ & $\mathrm{OH}$ & 80 & $53: 47$ \\
\hline $\begin{array}{l}i-\operatorname{Pr} \\
\mathrm{Ph}\end{array}$ & $\begin{array}{l}\mathrm{Ph} \\
\mathrm{Ph}\end{array}$ & $\begin{array}{l}\mathrm{OH} \\
\mathrm{OMe}\end{array}$ & $\begin{array}{l}97 \\
78\end{array}$ & $\begin{array}{l}83: 17 \\
64: 36\end{array}$ & $i-\operatorname{Pr}$ & & $\mathrm{OH}$ & 62 & $57: 43$ \\
\hline $\operatorname{Pr}$ & $\mathrm{Ph}$ & $\mathrm{OMe}$ & 98 & 71:29 & & & & & \\
\hline $\mathrm{Ph}$ & $\mathrm{Ph}$ & $\mathrm{CO}_{2} \mathrm{Me}$ & 73 & $68: 32$ & $\mathrm{Ph}$ & & $\mathrm{CO}_{2} \mathrm{Me}$ & 31 & 63:37 \\
\hline $\operatorname{Pr}$ & $\mathrm{Ph}$ & $\mathrm{CO}_{2} \mathrm{Me}$ & 41 & $77: 23$ & & & & & \\
\hline $\mathrm{Ph}$ & $\mathrm{PhCH}_{2}$ & $\mathrm{CO}_{2} \mathrm{Me}$ & 64 & $67: 33$ & $\operatorname{Pr}$ & & $\mathrm{CO}_{2} \mathrm{Me}$ & 40 & $57: 43$ \\
\hline
\end{tabular}

\section{Scheme 10}

The diastereoselectivity of the process, and the configurational stability of new chiral $\alpha$ aminonitriles were investigated. For the one-pot Strecker reaction, two mechanisms have been proposed: one going via an imine (or iminium ion) intermediate, the other via an aminol intermediate (Scheme 11). ${ }^{37}$ The imine route was more plausible in those cases where the Strecker reaction was carried out in organic solvents and in the presence of a dehydrating agent 
that could force the elimination of water. However, Tanaka et al. demonstrated that imines could be efficiently formed also in water by mixing aromatic aldehydes and amines, the Schiff bases separated from the aqueous medium as crystalline products in good yields. ${ }^{38}$ Computational studies on the effect of the structure of the amine on the formation of iminium intermediates with aldehydes in water showed that aminol and iminum species were intermediates with high barriers, especially for secondary cyclic amines such as proline methyl ester and pyrrolidine. ${ }^{39}$ In case of L-prolinols, because of the presence of a primary alcohol in the side chain, the formation of bicyclic 1,3-oxazolidines, as well as imine/imonium and aminol intermediates, could be possible. $^{40}$

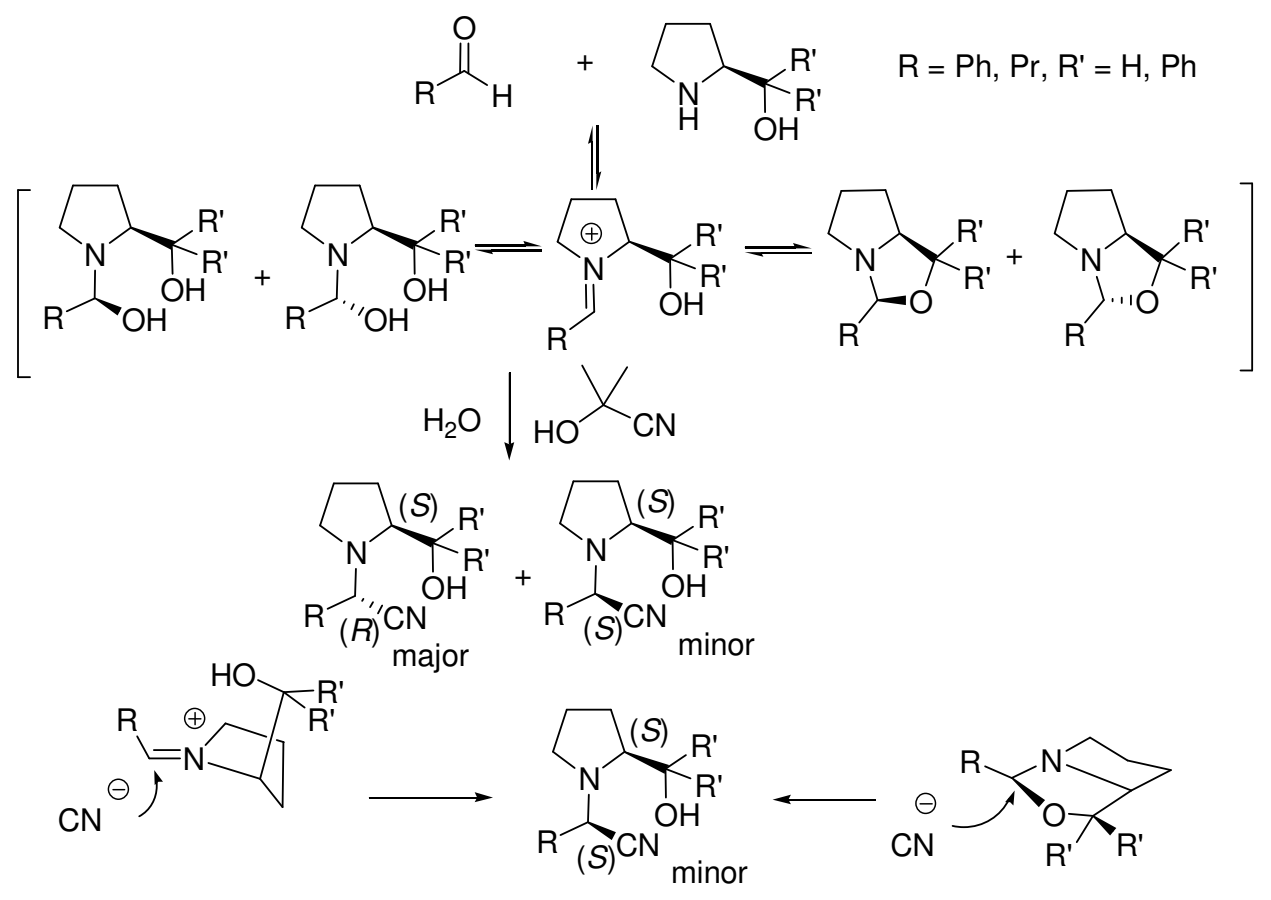

\section{Scheme 11}

\section{Enantioselective Strecker Reaction Using Metal Catalysts}

It is generally known that the chiral metal complexes act as versatile catalysts for a broad variety of asymmetric synthesis. But it was not until 1998 that the first asymmetric metal complex catalyzed Strecker reaction was reported. ${ }^{41}$ In recent years, the types of chiral metal complex catalysts based on Lewis acids, which comprised chiral aluminum, titanium, lanthanide, vanadium, ruthenium and magnesium complexed metal catalysts, were applied succcessfully to the asymmetric Strecker reaction. It is noteworthy that each catalyst requires the use of a specific $N$-substituent in order to obtain good results. Thus, the preferred type of $N$-substituent depends on the type of catalyst applied. 


\subsection{Using chiral aluminum(III) complexes}

Sigman and Jacobsen first reported the enantioselective Strecker reaction using chiral aluminum(III) complexes as a catalyst in $1998 .{ }^{41}$ Later, some successful exmples were developed in succession with different chiral aluminum(III) complexes as catalysts. Although catalytic asymmetric addition of cyanide to imines to generate $\alpha$-amino-protected nitriles (the Strecker reaction) has been extensively studied in the past, alternative, easier-to-handle reagents for this process are required for modern organic synthesis. To date, there are a limited number of reports utilizing alternative sources of cyanide other than $\mathrm{KCN} / \mathrm{HCN}$ or TMSCN for this important reaction. In 2009, Abell and Yamamoto found an aluminum complex 12 was high yields and enantioselective for the addition of cyanide to aldimines and ketimines (Scheme 12). ${ }^{42}$ The catalyst provided uniformly high enantioselectivity for aromatic, heteroaromatic, and aliphatic aldimines and ketimines using ethyl cyanoformate as the cyanide source.
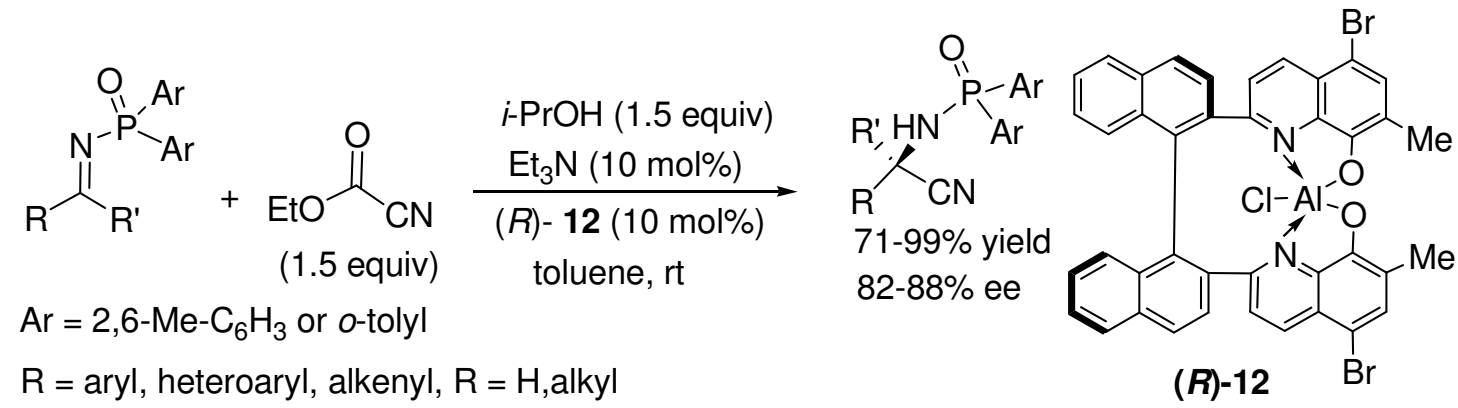

\section{Scheme 12}

In 2010, $\mathrm{Li}$ and co-workers ${ }^{43,44}$ reported the asymmetric Strecker reaction of N-phosphonyl imines 13 with $\mathrm{Et}_{2} \mathrm{AlCN}$. Excellent yields and enantioselectivities were obtained for a variety of aromatic aldimines by using catalytic amounts of either the amino alcohol 14, 3,3'-di-4-Phphenyl-BINOL $\mathbf{1 5}$ and primary free natural amino acids $\mathbf{1 6}$ as the ligand (Scheme 13 and Scheme 14). The N-phosphonyl group could be readily cleaved under mild conditions and enable purification of crude products by washing with hexane. The cleaved N,N-dialkyl diamine auxiliary could be recovered quantitatively. On the basis of the assignment of absolute configuration of the resulting products, a working model had been proposed and shown in Scheme 15 to explain the possible source of asymmetric induction. ${ }^{44}$ In this model, Nphosphonyl imine approaches the catalytic nucleophilic source of -CN from its less hindered side of hydrogen instead of the bulkier phenyl group of the chiral center of the catalyst. Although several conformational arrangements were possible, it was more likely for the $\mathrm{C}=\mathrm{N}$ bond to be arranged on the anti position of the Al-CN bond as shown in Scheme 15. 

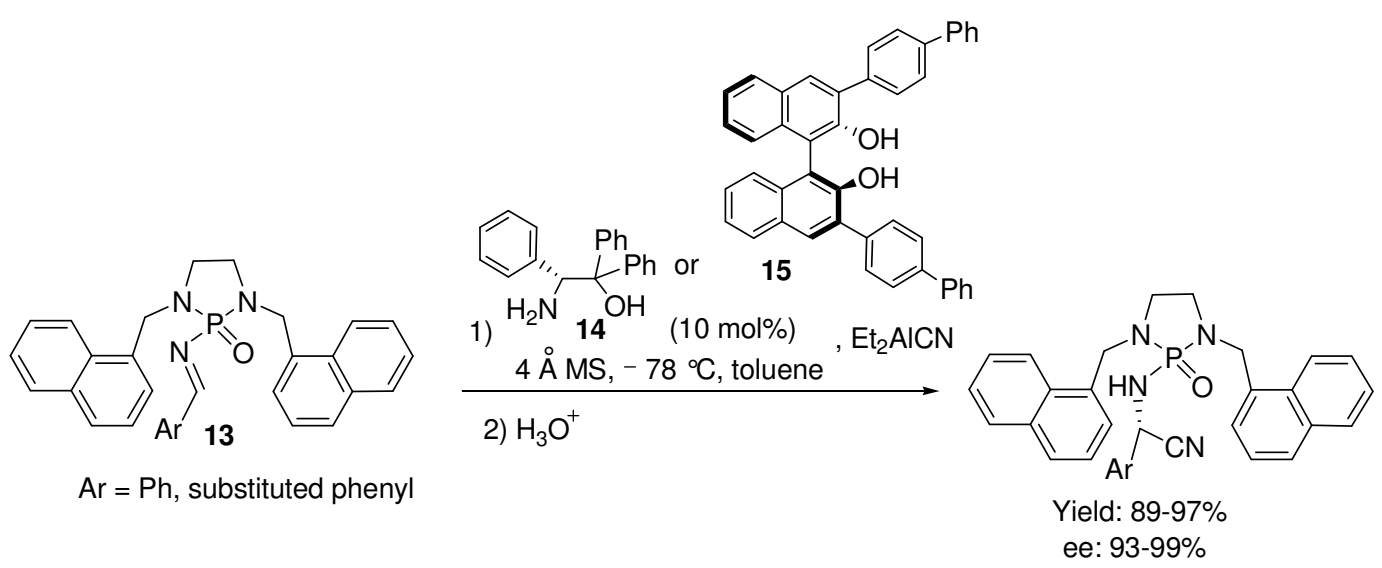

\section{Scheme 13}
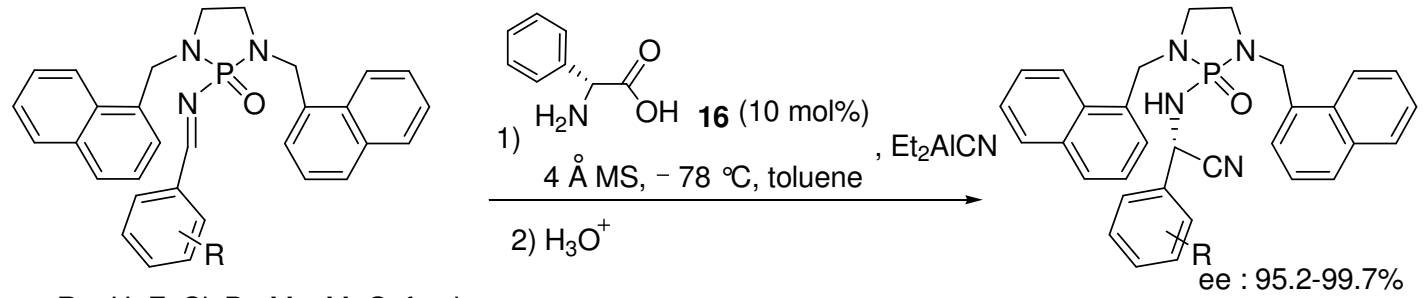

$\mathrm{R}=\mathrm{H}, \mathrm{F}, \mathrm{Cl}, \mathrm{Br}, \mathrm{Me}, \mathrm{MeO}$, furyl

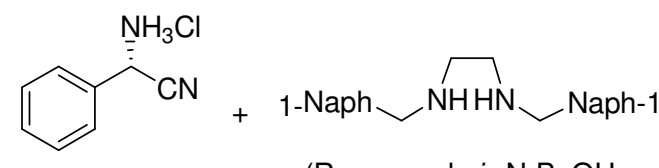

yield : $89-97 \%)$

aq. $\mathrm{HCl}, \mathrm{MeOH}$, r.t., $2 \mathrm{~h}$

(Recovered vis $\mathrm{N}-\mathrm{BuOH}$ extraction, quant)

\section{Scheme 14}

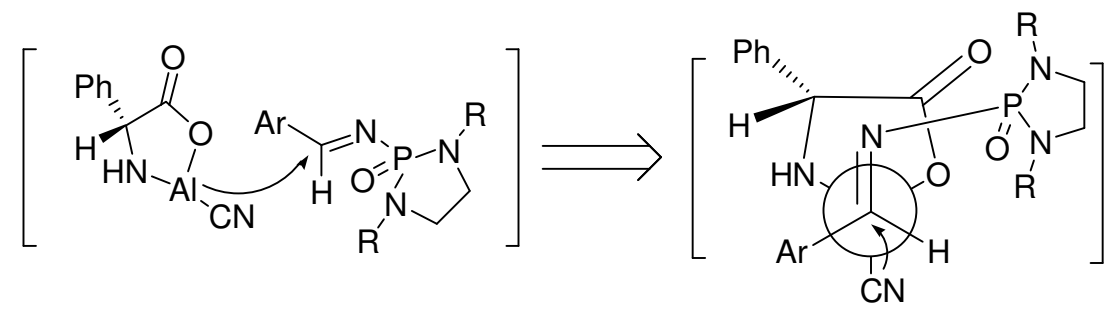

\section{Scheme 15}

The following year the group found that chiral $N$-phosphonylimines were efficient electrophiles for reaction with diethylaluminum cyanide, a non-volatile and inexpensive cyanide source (Scheme 16). ${ }^{45}$ The reaction produced chiral Strecker adducts, $\alpha$-aminonitriles, in excellent chemical yields (94-98\%) and diastereoselectivities (95:5 to >99\%). This synthesis was confirmed to follow the GAP chemistry (group-assistant-purification chemistry) process, which could avoid traditional chromatography and recrystallization purifications, i.e., the pure 
chiral $\alpha$-aminonitriles bearing a chiral $N$-phosphonyl group might be simply obtained by washing the solid crude products with hexane. The chiral $N$-phosphonyl auxiliary can easily be cleaved under mildly acidic conditions and quantitatively recycled by a single extraction with $n$-butanol.
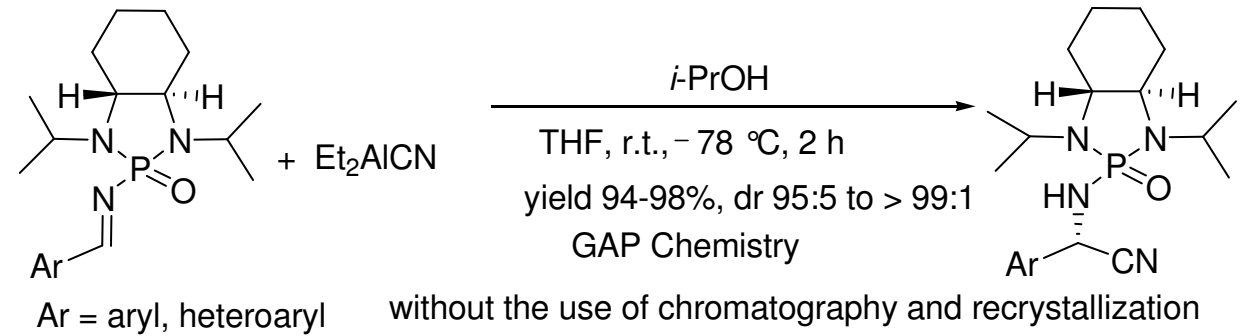

$\mathrm{Ar}=$ aryl, heteroaryl without the use of chromatography and recrystallization

\section{Scheme 16}

\subsection{Using chiral titanium(IV) complexes}

In 2007, Feng's group reported a self-assembled titanium catalyst for use in Strecker reactions of aldimines and ketimines (Scheme 17). ${ }^{46}$ Asymmetric activation of tropos biphenol 17 and $\mathrm{Ti}(\mathrm{OiPr})_{4}$ with cinchonine $\mathbf{1 8}$ generated a remarkably effective catalyst in situ for the asymmetric Strecker reaction of $N$-tosyl (Ts) imines under mild conditions. Various substrates including aldimines, aryl alkyl ketoimines, and unsymmetrical diaryl ketoimines were investigated, and most of them exhibited high enantioselectivities (up to $99 \%$ ee) as well as high reactivities.

\begin{tabular}{|c|c|c|c|c|c|}
\hline$\left\{\begin{array}{l}-T s \\
R^{2}+1.2\end{array}\right.$ & $\begin{array}{lr}\mathrm{SCN} & \frac{1}{1.2} \\
\text { equiv) } & i-\mathrm{P} \\
\text { to }\end{array}$ & $\begin{array}{l}\text { Ji-Pr })_{4} / 18 \\
1.0,5 \mathrm{~mol} \\
(1.2 \text { equiv } \\
2,-20{ }^{\circ} \mathrm{C} \\
20 \mathrm{~h}\end{array}$ & 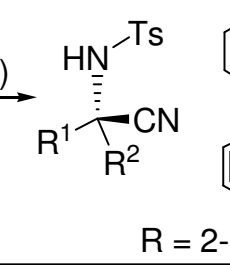 & $\mathrm{R}_{\mathrm{R}}^{\mathrm{O}}$ & $\mathrm{HO}, \mathrm{K}_{\mathrm{H}}^{\mathrm{N}}$ \\
\hline $\mathrm{R}$ & Yield (\%) & ee (\%) & $\mathrm{R}$ & Yield (\%) & ee (\%) \\
\hline $\mathrm{C}_{6} \mathrm{H}_{5}$ & $>99$ & $97(S)$ & 1-naphthyl & 92 & 91 \\
\hline $4-\mathrm{FC}_{6} \mathrm{H}_{5}$ & $>99$ & 96 & 2-naphthyl & 97 & 96 \\
\hline $4-\mathrm{ClC}_{6} \mathrm{H}_{5}$ & 97 & 93 & 2-furyl & 93 & 90 \\
\hline 4- $\mathrm{MeC}_{6} \mathrm{H}_{5}$ & $>99$ & 97 & 2-thienyl & 94 & 94 \\
\hline $3-\mathrm{MeC}_{6} \mathrm{H}_{5}$ & $>99$ & 94 & $(E)-\mathrm{PhCH}=\mathrm{CH}$ & 96 & 91 \\
\hline $2-\mathrm{MeC}_{6} \mathrm{H}_{5}$ & $>99$ & 79 & cyclohexyl & $>94$ & 94 \\
\hline $4-\mathrm{MeOC}_{6} \mathrm{H}_{5}$ & $>99$ & 97 & $i-\operatorname{Pr}$ & 96 & 84 \\
\hline$\left\langle 0 y^{2}\right.$ & $>99$ & $97(S)$ & $n-\mathrm{C}_{5} \mathrm{H}_{11}$ & 92 & 91 \\
\hline
\end{tabular}

\section{Scheme 17}


In 2008, Wünnemann et al. reported the synthesis of a library of $N$-arenesulfonyl-1,3oxazolidinyl-substituted biphenyldiols 19, which were subsequently examined as ligands in enantioselective Strecker reactions (Scheme 18). ${ }^{47}$ By employing $10 \mathrm{~mol} \%$ of 19-Ti(Oi-Pr) $)_{4}$ as the catalyst and $i-\mathrm{PrOH}$ as the additive, the Strecker reaction of various aldimines proceeded well to furnish the desired products with moderate to good yields and ee values.

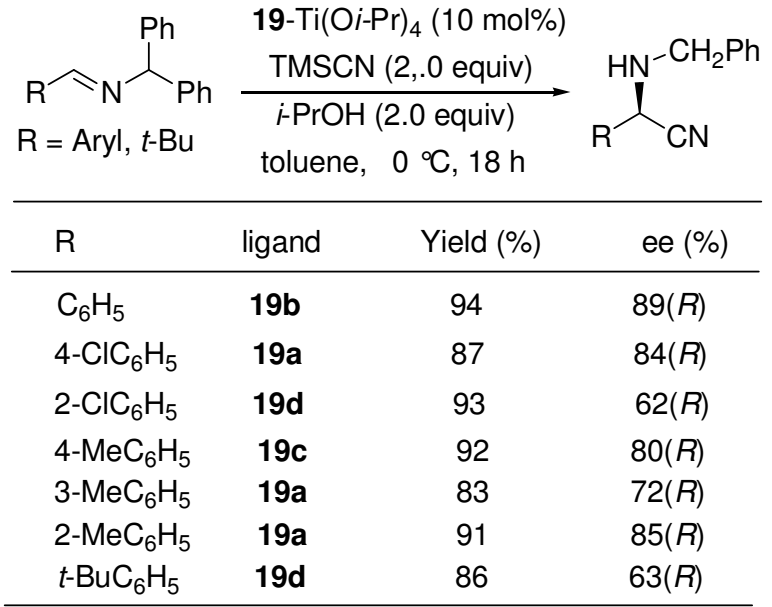

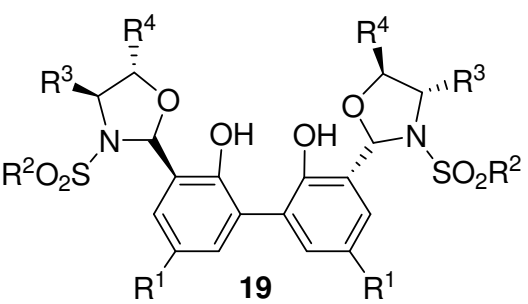

19a: $\mathrm{R}^{1}=t-\mathrm{Bu} ; \mathrm{R}^{2}=\mathrm{Mes} ; \mathrm{R}^{3}=i-\mathrm{Pr} ; \mathrm{R}^{4}=\mathrm{H}$

19b: $\mathrm{R}^{1}=t-\mathrm{Bu} ; \mathrm{R}^{2}=\mathrm{Mes} ; \mathrm{R}^{3}=t-\mathrm{Bu} ; \mathrm{R}^{4}=\mathrm{H}$

19c: $\mathrm{R}^{1}=H ; \mathrm{R}^{2}=$ Mes; $\mathrm{R}^{3}=t-M e s ; \mathrm{R}^{4}=\mathrm{H}$

19d: $R^{1}=t-B u ; R^{2}=$ Mes; $R^{3}=s-B u ; R^{4}=H$

\section{Scheme 18}

In the same year, North and co-workers converted four amino acids (alanine, valine, phenylalanine and phenylglycine) into $\mathrm{C} 1$-symmetrical salen ligands and complexed to titanium, vanadium, copper and cobalt 20 (Scheme 19). ${ }^{48}$ The resulting complexes were used as asymmetric catalysts for asymmetric cyanohydrin synthesis, asymmetric Strecker reactions, asymmetric synthesis of $\alpha$-methyl amino acids and asymmetric Darzens condensations. Satisfactory levels of asymmetric induction were obtained from reactions in which the (salen)metal complex acts as a chiral Lewis acid, but low levels of asymmetric induction were obtained from reactions carried out under solid-liquid phase-transfer conditions.

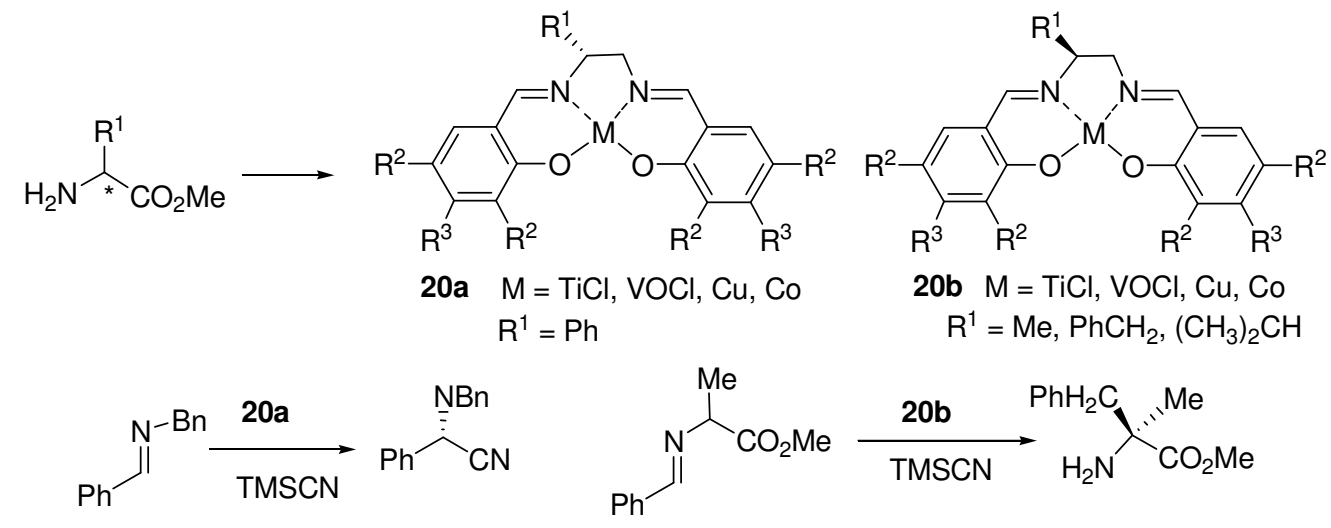

\section{Scheme 19}


Banphavichit et al. developed a practical and efficient method for synthesis of optically active $\alpha$-arylaminonitriles by Strecker reaction using a Ti complex of the structurally simple chiral amino alcohol ligand 21 at low catalyst loading $(2.5 \mathrm{~mol} \%)$ (Scheme 20). ${ }^{49}$ The $\mathrm{N}$ benzhydryl $\alpha$-arylaminonitrile intermediates were prepared in excellent yield (89-99\%) and enantiomeric purity ( 96 to $>98 \%$ ee) by enantioselective cyanation of aldimines with TMSCN $/ i$ $\mathrm{PrOH}$ in the presence of $2.5 \mathrm{~mol} \%$ of an easily prepared Ti/chiral amino alcohol complex at 0 ${ }^{\circ} \mathrm{C}$, without requiring slow addition of the cyanating agent. The easily racemized $\alpha$-aminonitrile intermediates were efficiently hydrolyzed by an aqueous $\mathrm{HCl} / \mathrm{TFA}$ mixture to give the arylglycine derivatives in good yield (60-92\%) and moderate to excellent enantiomeric purity (85-98\% ee).

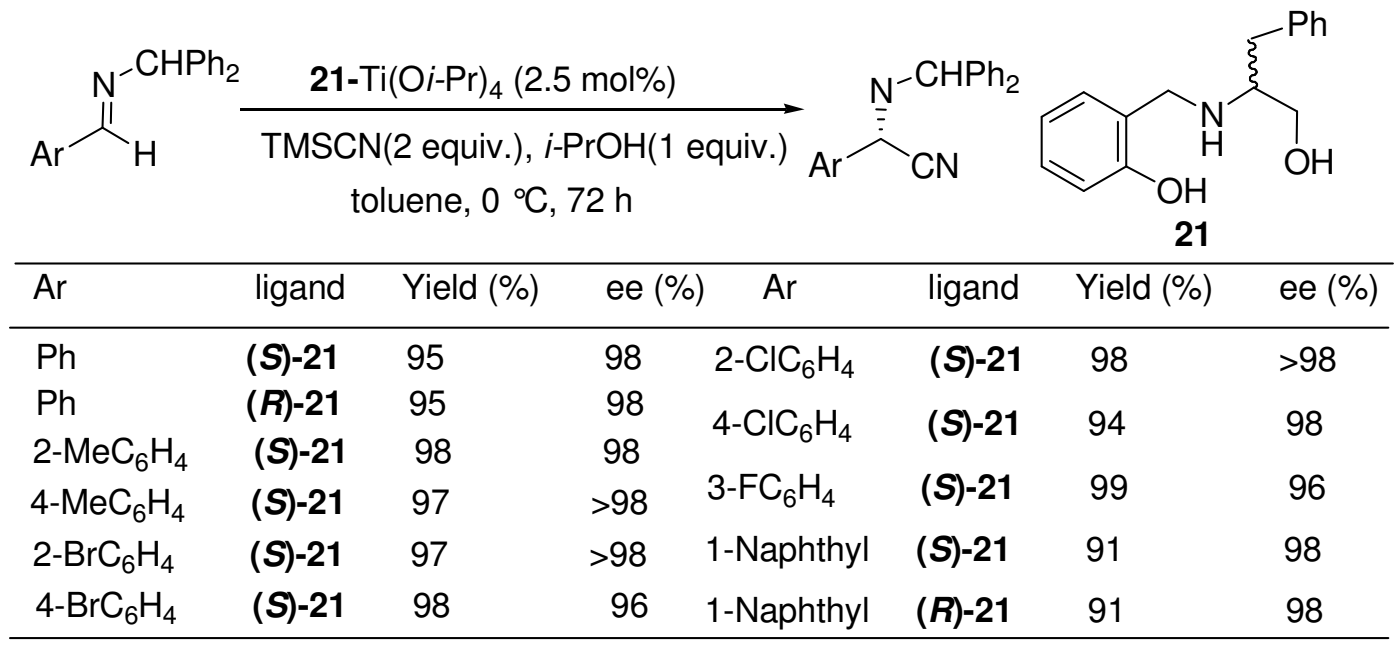

\section{Scheme 20}

Seayad, Chai et al. have described a highly enantioselective (up to $98 \%$ ee) cyanation of imines using HCN as the cyanide source at room temperature (Scheme 21 and Scheme 22). ${ }^{50}$ In this operationally simple process, the catalyst generated from a partially hydrolyzed titanium alkoxide (PHTA) and ( $S$ )- $N$-salicyl- $\beta$-amino alcohol ligand 22 (Scheme 23), catalyzed the cyanation of imines in a short reaction time. The methodology offered the possibility of utilizing the Strecker reaction economically for large-scale synthesis of $\alpha$-amino acids.

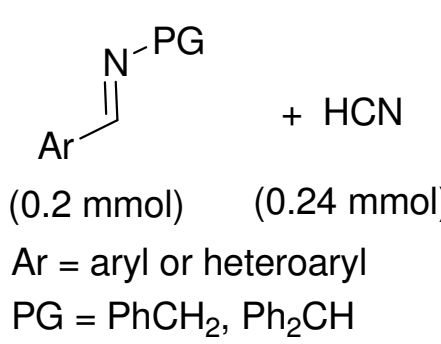

\section{Scheme 21}




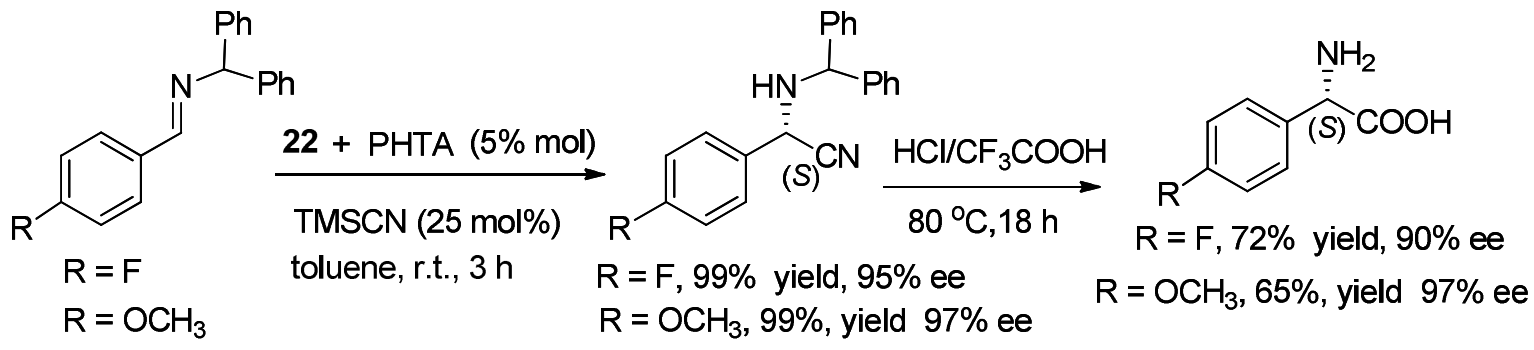

\section{Scheme 22}

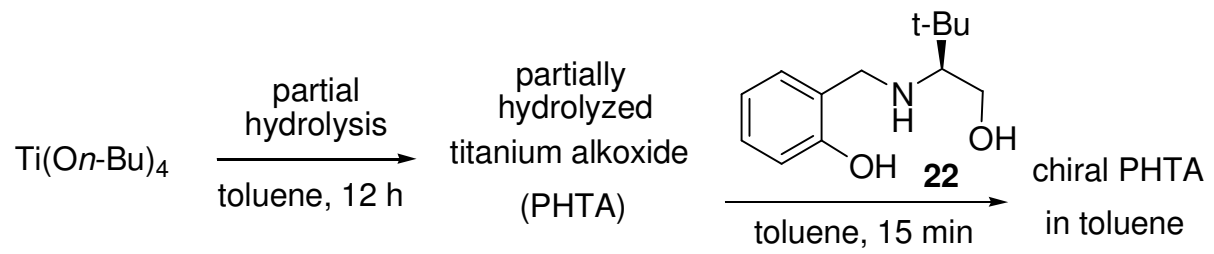

\section{Scheme 23}

The proposed catalytic cycle (Scheme 24) would explain the possible role of TMSCN in the reaction. (i) the IR absorptions in the range of $420-700 \mathrm{~cm}^{-1}$ suggest the possible presence of a Ti-O-Ti bridged complex in solution. (ii) Under the reaction conditions, no IR absorptions around $2100 \mathrm{~cm}^{-1}$ as expected for Ti-CN vibrations is observed. The cyanide group was either weakly bonded to titanium or the intermediate with a Ti-CN bond might be extremely shortlived. (iii) The reactivity of TMSCN was 4.8 times faster in the presence of catalyst and this indicated the possible activation of TMSCN prior to reaction with the imine II. (iv) In the presence of $10 \mathrm{~mol} \%$ of TMSCN, the cyanation with $\mathrm{HCN}$ was significantly faster than that of either TMSCN or HCN alone. Finally (v), the overall cyanation with TMSCN/protic additive and HCN/TMSCN system proceeded with comparable reactivity and this suggested the possibility of initial addition by TMSCN. HCN presumably acted as proton source and thus accelerates the formation of amino nitriles III and regenerated the TMSCN for further addition to imines. A similar catalytic cycle was proposed by Shibasaki et al. for the cyanation of $N$-fluorenylimines using the mixture of TMSCN and $\mathrm{HCN}^{50}$ The proposed mechanism did not provide a rationale for the observed enantioselectivities and further investigation of the reaction intermediates and the structure of the catalyst was needed. 


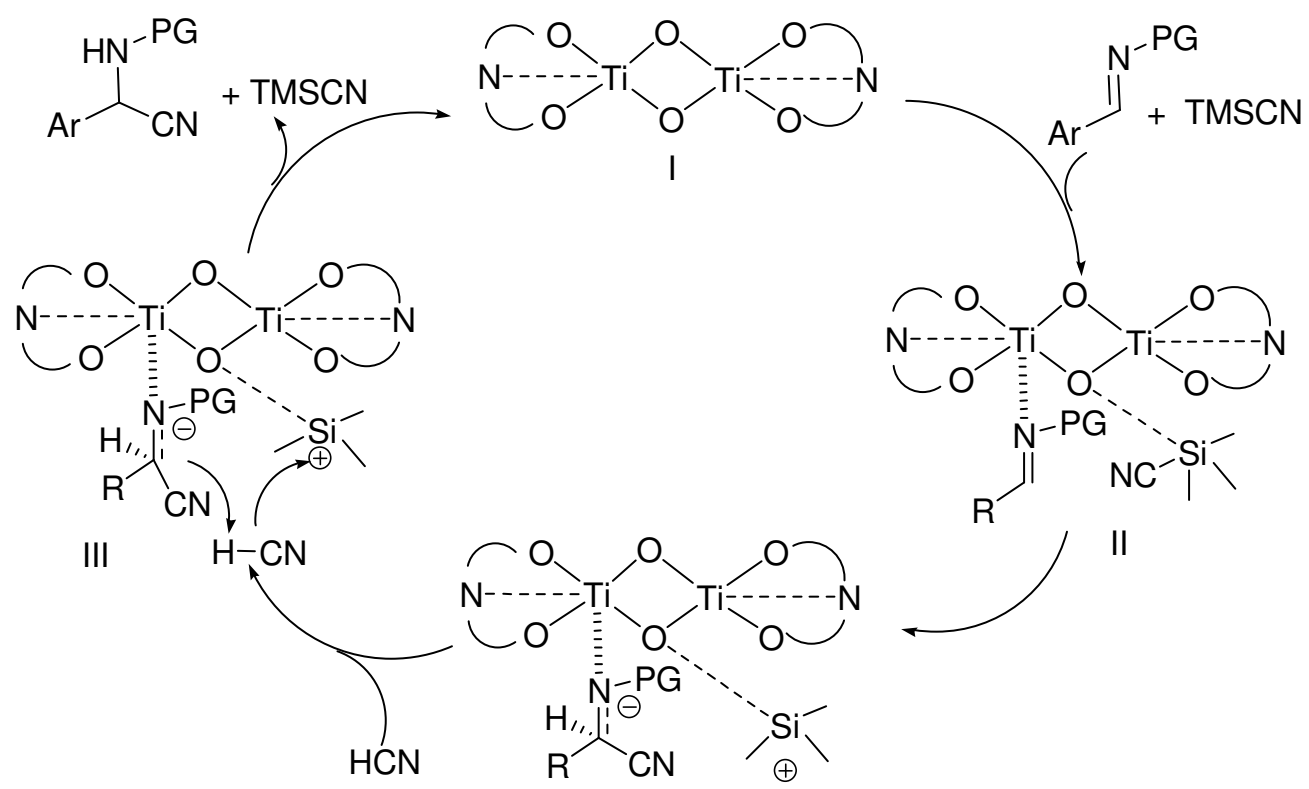

\section{Scheme 24}

Later, it was revealed by Chai and co-workers ${ }^{51}$ that similar results could also be achieved by using HCN (1.2 equiv) as the cyanide reagent in the presence of catalytic amounts of TMSCN $(10-25 \mathrm{~mol} \%)$. These results were in fact very similar to those observed by the Shibasaki group. $^{52}$

\subsection{Using chiral lanthanoide(III) complexes}

Previously, Shibasaki's group had found that lanthanide complexes were very efficient catalysts for the Strecker reaction with ketimines. ${ }^{53-55}$ In 2009, Ishihara and coworkers developed a catalytic enantioselective Strecker reaction catalyzed by novel chiral lanthanum(III)-binaphthyl disulfonate 23 complexes (Scheme 25). ${ }^{56}$ The key to promoting the reactions was a semistoichiometric amount of $\mathrm{AcOH}$ or $i-\mathrm{PrCO}_{2} \mathrm{H}$, which took advantage of $\mathrm{HCN}$ generation in situ. The corresponding cyanation products were obtained in high yields and with high enantioselectivities.

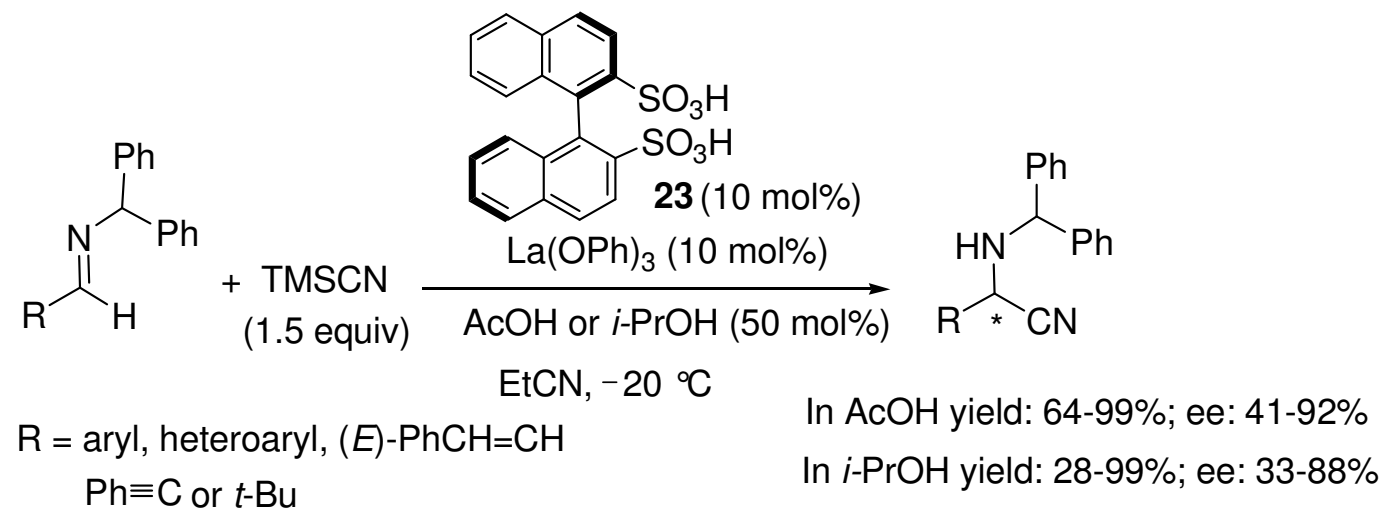

\section{Scheme 25}


In 2009, Karimi and Maleki explored the highly enantioselective Strecker hydrocyanation of a wide range of aromatic, $\alpha, \beta$-unsaturated, heterocyclic, and aliphatic aldimines in the presence of catalytic amounts of $\mathrm{Yb}(\mathrm{OTf})_{3}$-pybox 24 complexes. ${ }^{57}$ Various aldimines, including aromatic, $\alpha, \beta$-unsaturated, and aliphatic aldimines were tested under these conditions. The corresponding $\alpha$-amino nitriles were obtained in excellent yields and moderate to excellent enantioselectivities (Scheme 26). In the following year, Hunt et al. used a heterogeneous catalyst 25 with $\mathrm{Yb}(\mathrm{OTf})_{3^{-}}$ pybox immobilized in a novel self-assembled ionic liquid phase hybrid silica (Scheme 27). ${ }^{58}$ The catalyst has been successfully applied for the asymmetric Strecker hydrocyanation of aldimines. This catalytic system can be reused for at least 6 times without any significant loss of activity and enantioselectivity.

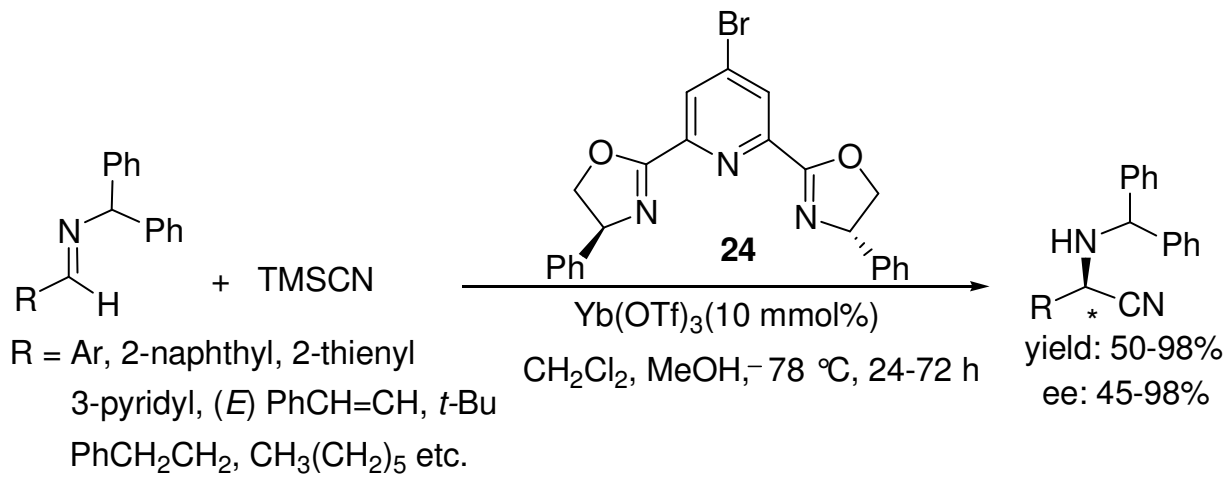

\section{Scheme 26}

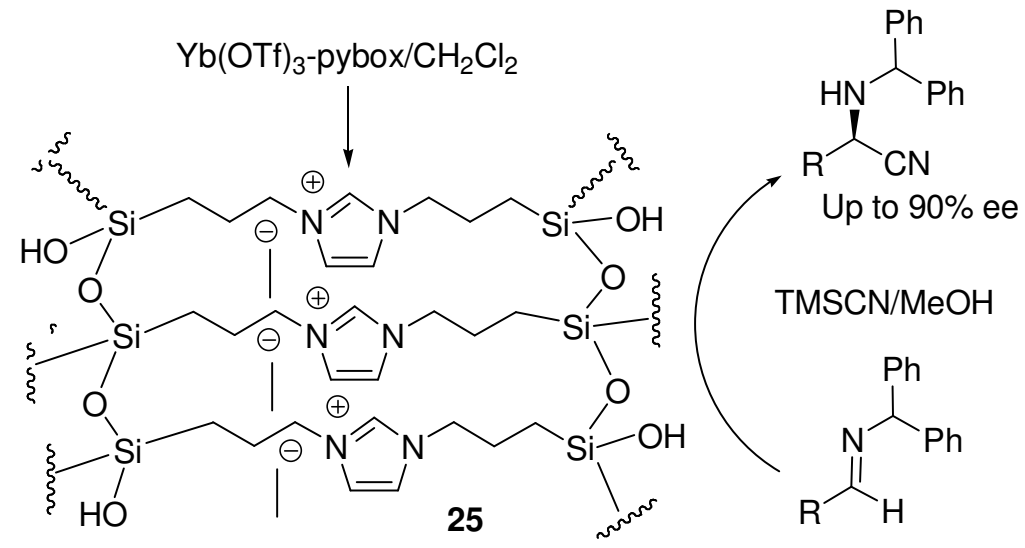

\section{Scheme 27}

\subsection{Using chiral vanadium(V) complexes}

In 2005, North's group reported that a vanadium(V)-salen complex efficiently catalyzed the asymmetric addition of cyanide to $N$-benzyl-protected aldimines giving $\alpha$-amino nitriles with up to $81 \%$ ee. ${ }^{59}$ Later, the group studied the asymmetric synthesis of cyanohydrins using a 
vanadium(V)-salen complex as a catalyst. ${ }^{60}$ In 2010, Khan et al. reported a chiral dimeric vanadium(V) salen complex $26(10 \mathrm{~mol} \%)$ derived from 5,5-methylenedi-[(S,S)-[N-(3-tertbutylsalicylidine)- $N^{\prime}$-(3',5'-di-tert-butylsalicylidene)]-1,2-cyclohexanediamine] with vanadyl sulfate followed by auto oxidation was used as efficient catalyst for enantioselective Strecker reaction of $N$-benzylimines with TMSCN at $-30{ }^{\circ} \mathrm{C}$ (Scheme 28). ${ }^{61}$ An excellent yield (92\%) of $\alpha$-aminonitrile with high chiral induction was obtained (ee up to $94 \%$ ) in the case of 2-methoxy substituted $N$-benzylimines in $10 \mathrm{~h}$. The catalytic system worked well up to four cycles with retention of enantioselectivity. The probable catalytic cycle for the enantioselective Strecker reaction is shown in Scheme 29, where the imine was polarized by the weak interaction through the lone pair of electrons present on it with metal center of the catalyst followed by the nucleophilic addition of cyanide ion ( $\mathrm{HCN}$ was generated by the reaction of $\mathrm{H}_{2} \mathrm{O}$ and TMSCN) to the polarized carbon of imines, resulting in the formation of the product and liberation of the catalyst to take part in another catalytic cycle.

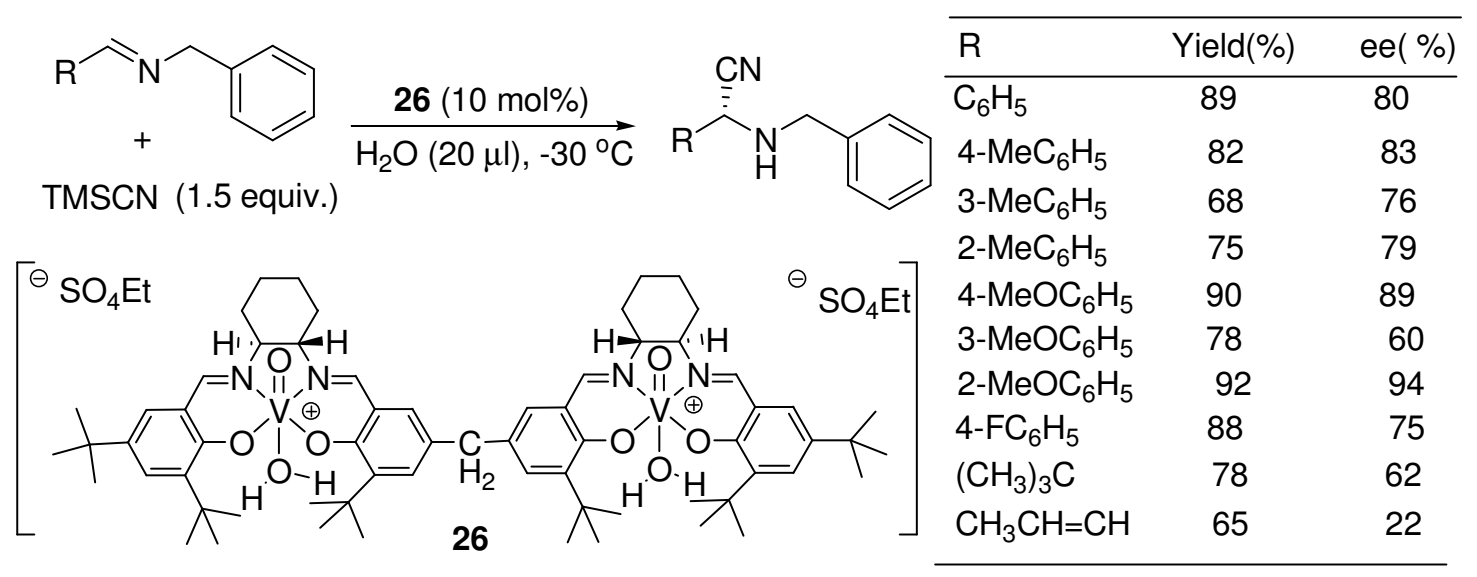

\section{Scheme 28}

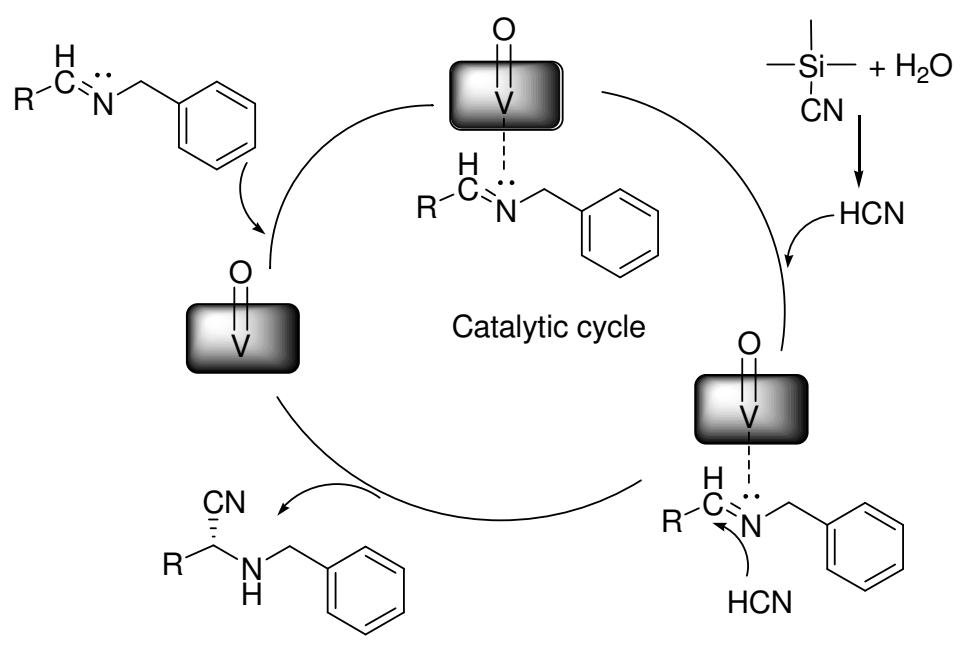

\section{Scheme 29}


Recently, Esteves et al. synthesized four new heterogeneous catalysts by covalent attachment of vanadium(V) and aluminum(III) salen complexes to polystyrene polymers, namely, Merrifield and JandaJel resins. ${ }^{62}$ The solid catalysts were characterized by analytical and spectroscopic techniques and tested in the asymmetric addition of hydrogen cyanide (generated in situ from TMSCN) to $N$-benzyl benzylimine (Strecker type reaction). Heterogeneous vanadium(V) catalysts are more efficient than the $\mathrm{Al}(\mathrm{III})$ catalysts, as expected from comparison with the corresponding homogeneous systems (Scheme 30). The activity of the vanadium(V) heterogeneous catalysts was similar to the homogenous counterpart (after $4 \mathrm{~h}$ of reaction at -40 ${ }^{\circ} \mathrm{C}$ using $10 \mathrm{~mol} \%$ of catalysts), while the enantiomeric excess was slightly inferior to the one obtained with the corresponding homogeneous catalysts. The Janda-vanadium(V) heterogeneous catalyst could be reused by simple filtration up to three times without significative loss of conversion and enantioselectivity. This was the first study dedicated to the synthesis of asymmetric amino acids through the Strecker reaction using heterogeneous salen catalysts.

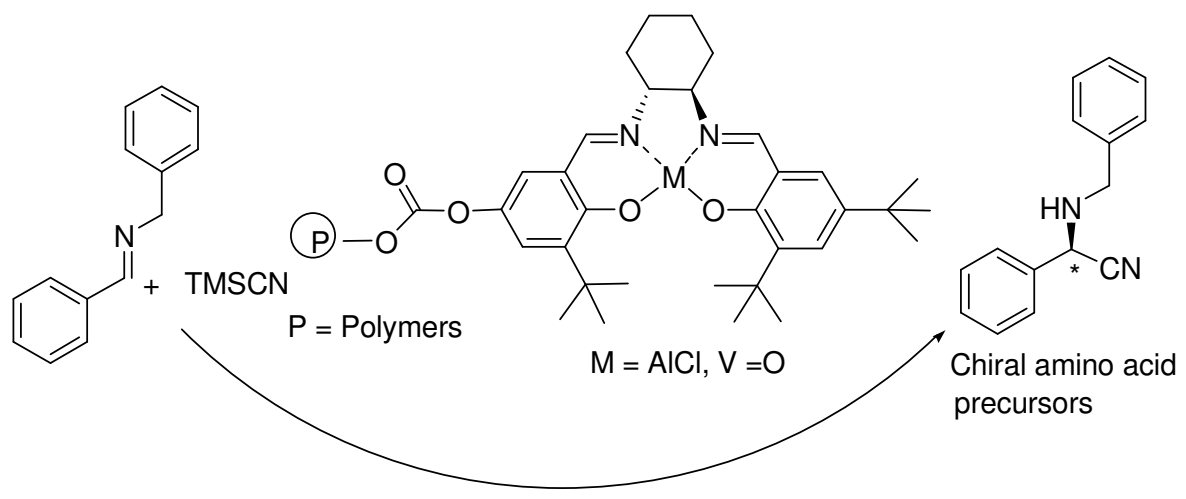

\section{Scheme 30}

\subsection{Using chiral ruthenium(II) complexes}

In 2012, Ohkuma et al. found the combined systems of phenylglycinate/BINAP/Ru(II) complex 27 and $\mathrm{Li}$ compounds could act as highly reactive and enantioselective catalysts for cyanosilylation and hydrocyanation of aldehydes, $\alpha$-keto esters, $\alpha, \beta$-unsaturated ketones, and $N$ protected aldimines. ${ }^{63,64}$ The Strecker-type reaction with the $(S, S, S)-27 / \mathrm{PhOLi}$ catalyst system was applied to a variety of $\mathrm{N}$-protected aldimines. As we expected, $\mathrm{N}$-tert-butoxycarbonyl (Boc) and $N$-benzoyl (Bz) imines were cyanated with a high level of enantioselectivity (Scheme 31 ). The reactivity and selectivity were significantly decreased in the reaction of the $N$-benzyl (Bn) imine. Various aromatic, heteroaromatic, and aliphatic $\mathrm{N}$-Cbz aldimines were cyanated with high reactivity and enantioselectivity. An excellent ee value of $99 \%$ was obtained in the reaction of the $3^{\prime}$-bromo imine at $-20^{\circ} \mathrm{C}$. The reaction of the sterically hindered tert-butylimine with an $\mathrm{S} / \mathrm{C}$ of 5000 at $0{ }^{\circ} \mathrm{C}$ was completed in $2 \mathrm{~h}$. The $4^{\prime}-\mathrm{CF}_{3}$-phenylimine and $n$-propyl imine reacted with low to moderate enantioselectivity, possibly due to the competitive base-catalyzed achiral cyanation. 


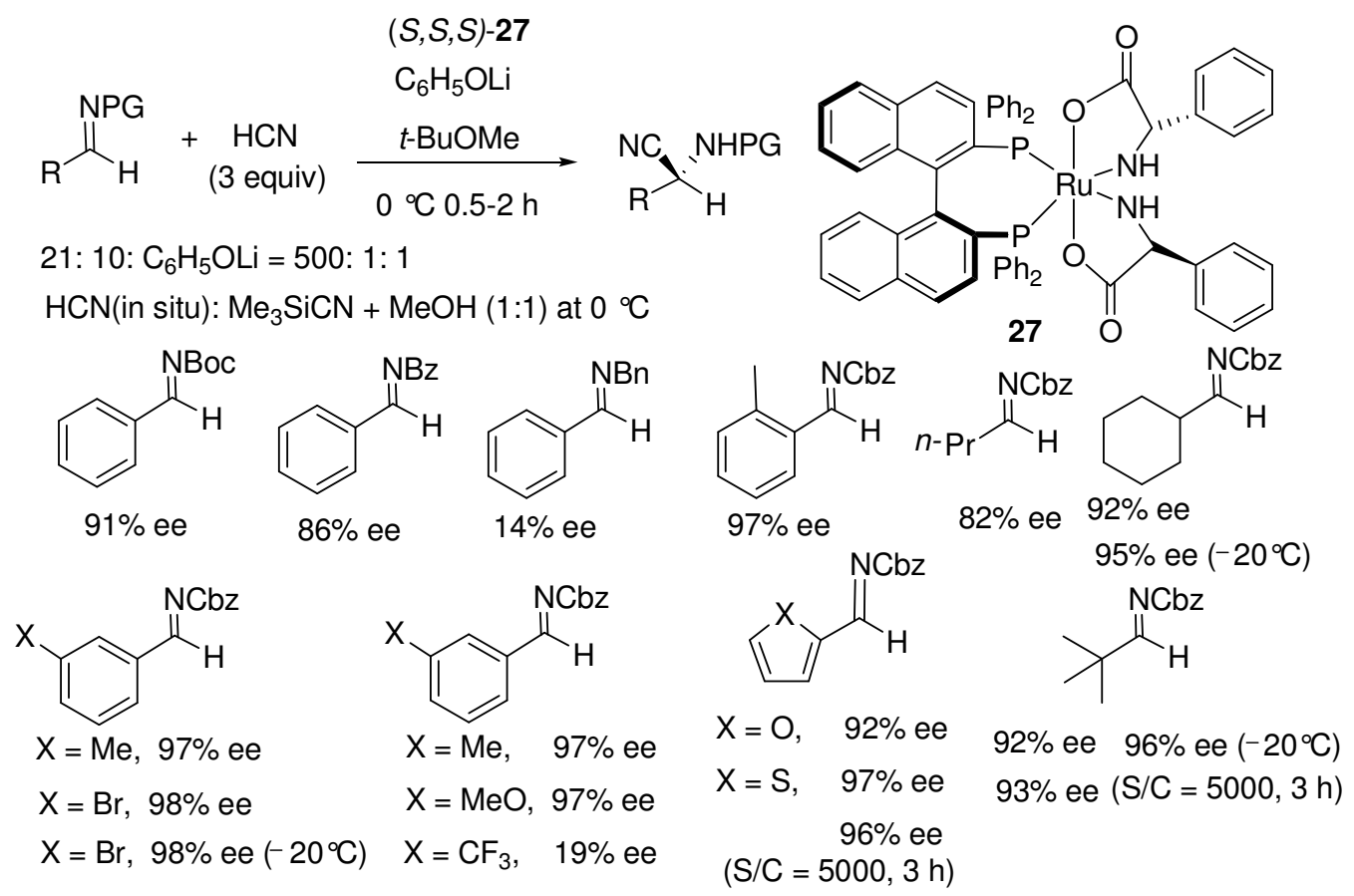

\section{Scheme 31}

\subsection{Using chiral magnesium(II) complexes}

In 2013, Sakai et al. developed an asymmetric Strecker-type reaction of various nitrones with acetone cyanohydrin using a magnesium- $(R, R)$-tartramide complex to successfully prepare optically active $(S)$ - $\alpha$-amino nitrile derivatives in excellent yield (Scheme 32 ). ${ }^{65}$ Thereby, the acetone cyanohydrin serves as a less hazardous and easy-to-handle synthetic equivalent of HCN and TMSCN. The reaction mechanism was proposed to proceed as follows: first, the reaction of cyanohydrin and the $(R, R)$-tartramide 28 with $\mathrm{MeMgBr}$ forms the corresponding bromomagnesium salt. The tartramide magnesium salt might be further deprotonated by DBU to form a magnesium ate-complex which coordinates the nitrone. Transfer of the cyano group from the cyanohydrin magnesium salt to the nitrone occurs from the $R e$ face, forming specifically the $(S)$-enantiomer.

One possible reaction pathway was shown in Scheme 33. When 30 and $(R, R)$-BTMTA are treated with 2 equiv of $\mathrm{MeMgBr}$, bromomagnesium salts $\mathbf{3 2}$ and $\mathbf{3 3}$ are formed. By the addition of 0.2 equiv of DBU, deprotonation from 33 might occur to furnish a tartramide magnesiumate complex 34, to which the nitrone 29 coordinates. The subsequent transcyanation proceeds from the re-face of the nitrone to afford the product $\mathbf{3 1}$ with a preference for the $(S)$-enantiomer. However, the effect of amide substituents is still not well-elucidated. 
<smiles>[R7]C([R7])=[N+]([O-])[O-]</smiles>

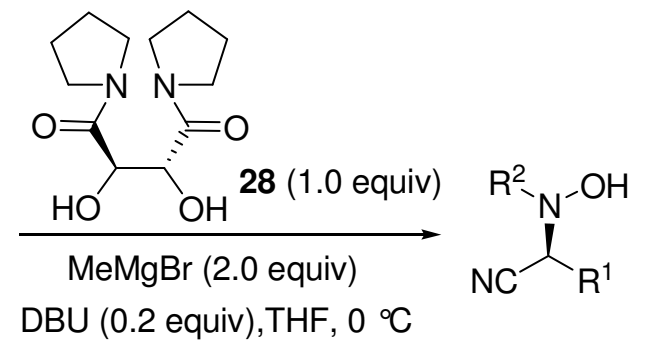<smiles>N#C[C@@H](N=Cc1ccccc1)c1ccccc1</smiles><smiles>CN(O)[C@H](C#N)c1ccccc1</smiles><smiles>N#C[C@@H](Nc1ccccc1)c1ccccc1</smiles><smiles>N#C[C@H](c1ccccc1)N(O)C(O)c1ccccc1</smiles><smiles>COc1ccc([C@H](C#N)NO)cc1</smiles>

22 h, yield: $80 \% 12$ h, yield: $47 \%$ ee: $89 \%$ ee: $72 \%$

$21 \mathrm{~h}$, yield: $6 \%$ ee: $63 \%$

$21 \mathrm{~h}$, yield: $58 \%$ ee: $96 \%$<smiles>N#C[C@H](Nc1ccccc1)c1cccc2ccccc12</smiles>

$41 \mathrm{~h}$, yield: $89 \%$ ee: $85 \%$<smiles>N#C[C@@H](NCc1ccccc1)c1ccc2ccccc2c1</smiles>

$41 \mathrm{~h}$, yield: $73 \%$ ee: $96 \%$<smiles>N#C[C@@H](NO)[15C](Br)(Br)Br</smiles><smiles>ONCCc1ccccc1</smiles><smiles></smiles>

22 h, yield: $90 \%$ ee: $87 \%$
$21 \mathrm{~h}$, yield: $72 \%$ ee: $90 \%$<smiles>CC(N)C#N</smiles>

$4 \mathrm{~h}$, yield: $95 \%$ ee: $79 \%$<smiles>N#C[C@@H](C1CCCCC1)N(O)Cc1ccccc1</smiles>

$21 \mathrm{~h}$, yield: $87 \%$ ee: $90 \%$
$21 \mathrm{~h}$, yield: $88 \%$ ee: $93 \%$

$$
\text { ee: } 96 \%
$$

2 h, yield: $94 \%$ ee: $97 \%$
$6 \mathrm{~h}$, yield: $97 \%$ ee: $73 \%$

\section{Scheme 32}
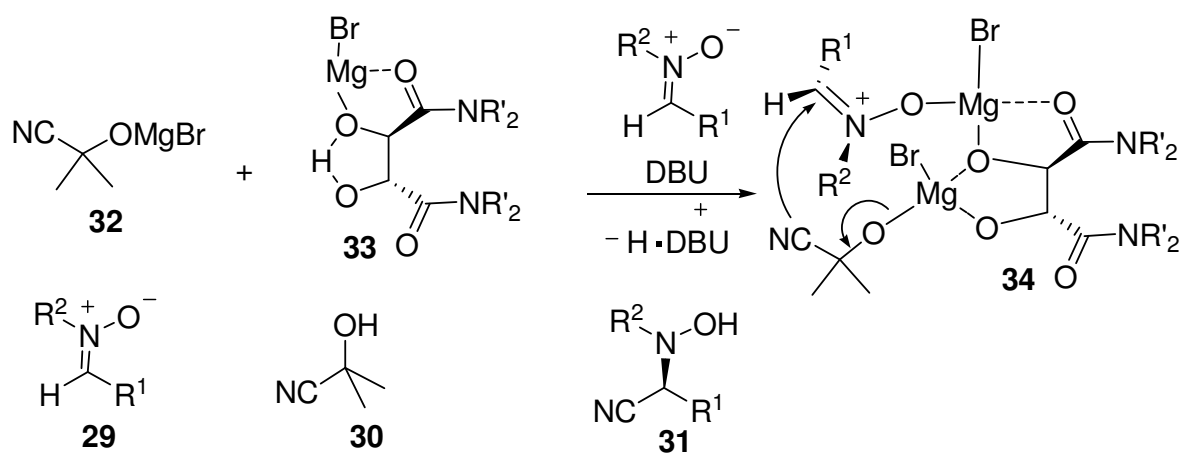

\section{Scheme 33}

In addition, zirconium-based complexes as catalysts in asymmetric Strecker reaction also showed highly efficient and good enantioselectivity. ${ }^{66}$ Typically, the catalytic asymmetric Strecker reaction with metal complexes show high catalytic capability and could be achieved with very low catalyst loading and higher enantioselectivities. Chiral metal complexes represent 
an interesting and important group of catalysts for the catalytic enantioselective addition of cyanide donors to imines. In general, aromatic imines are good substrates for all of those type of catalysts. Sometimes, $\alpha$-aliphatic imines as substrates can also obtained high enantioselectivities in case of suitable catalysts.

\section{Enantioselective Strecker Reactions using Organocatalysts}

Asymmetric organocatalysis is the field wherein small organic molecules efficiently and selectively catalyze organic transformations in absence of metals. The research field of organocatalysis has developed rapidly and can now be seen as a third pillar of asymmetric catalysis beside metal and biocatalysis. Numerous basic organocatalytic protocols for very efficient and highly stereoselective carbon-carbon and carbon-heteroatom bond formations are now part of the strategic arsenal of synthetic chemistry. ${ }^{67,68}$ The Lipton group first reported the chiral diketopiperazine-catalyzed hydrocyanation of aldimines in $1996 .{ }^{11}$ They investigated the stereoselective addition of $\mathrm{HCN}$ to a variety of imines catalyzed by synthetically obtained diketopiperazine-based organocatalyst 35 (Scheme 34). Catalyst 35 was found to be extremely enantioselective in this reaction (ee up to $>99 \%$ ). Later, a number of chiral organocatalysts for asymmetric Strecker reaction have been developed. These catalysts include the phase-transfer catalysts, $N$-galactosyl[2,2]-paracyclophane carbaldimines, BINOL phosphate derivatives, ureas and thioureas, bisformamide, $N$-oxides, etc.

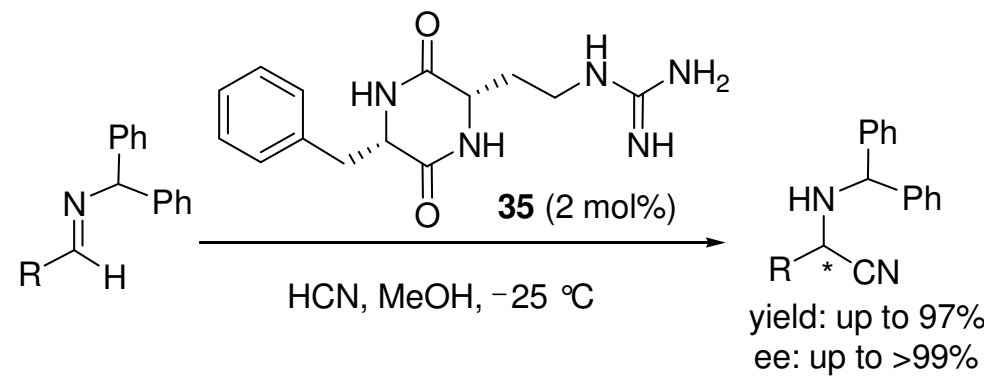

\section{Scheme 34}

\subsection{Cinchona alkaloid-catalyzed reactions}

In 2009, Bräse and coworkers reported an efficient, organocatalytic enantioselective synthesis of $N$-arylsulfonyl $\alpha$-amino nitriles from the corresponding $\alpha$-amido sulfones had been developed using quinine-catalyzed catalyst 36 (Scheme 35). ${ }^{69}$ This quinine-catalyzed Strecker reaction provided the corresponding cyanated products in good yields and enantioselectivities. Khan et al. also developed a straightforward approach for catalytic asymmetric Strecker reaction of aldehydes with a secondary amine in the presence of sodium fluoride using hydroquinine as catalyst 36 (Scheme 36). ${ }^{70}$ The catalytic system gave $\alpha$-aminonitriles in excellent yields (up to 95\%) and high enantioselectivities (er up to 94:6). The efficacy of the chiral product was successfully fulfilled in the improved synthesis of (S)-Clopidogrel (an antiplatelet agent). 


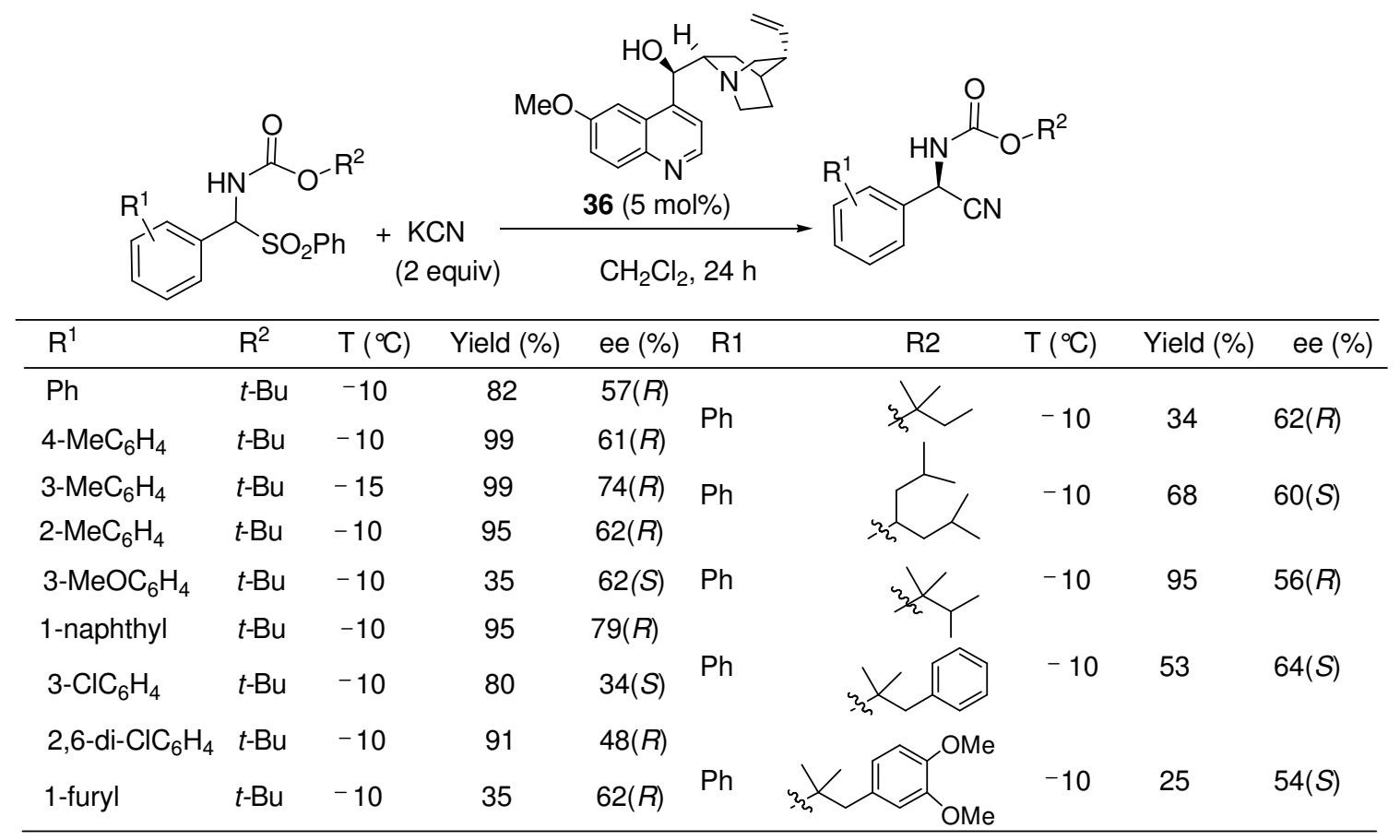

\section{Scheme 35}

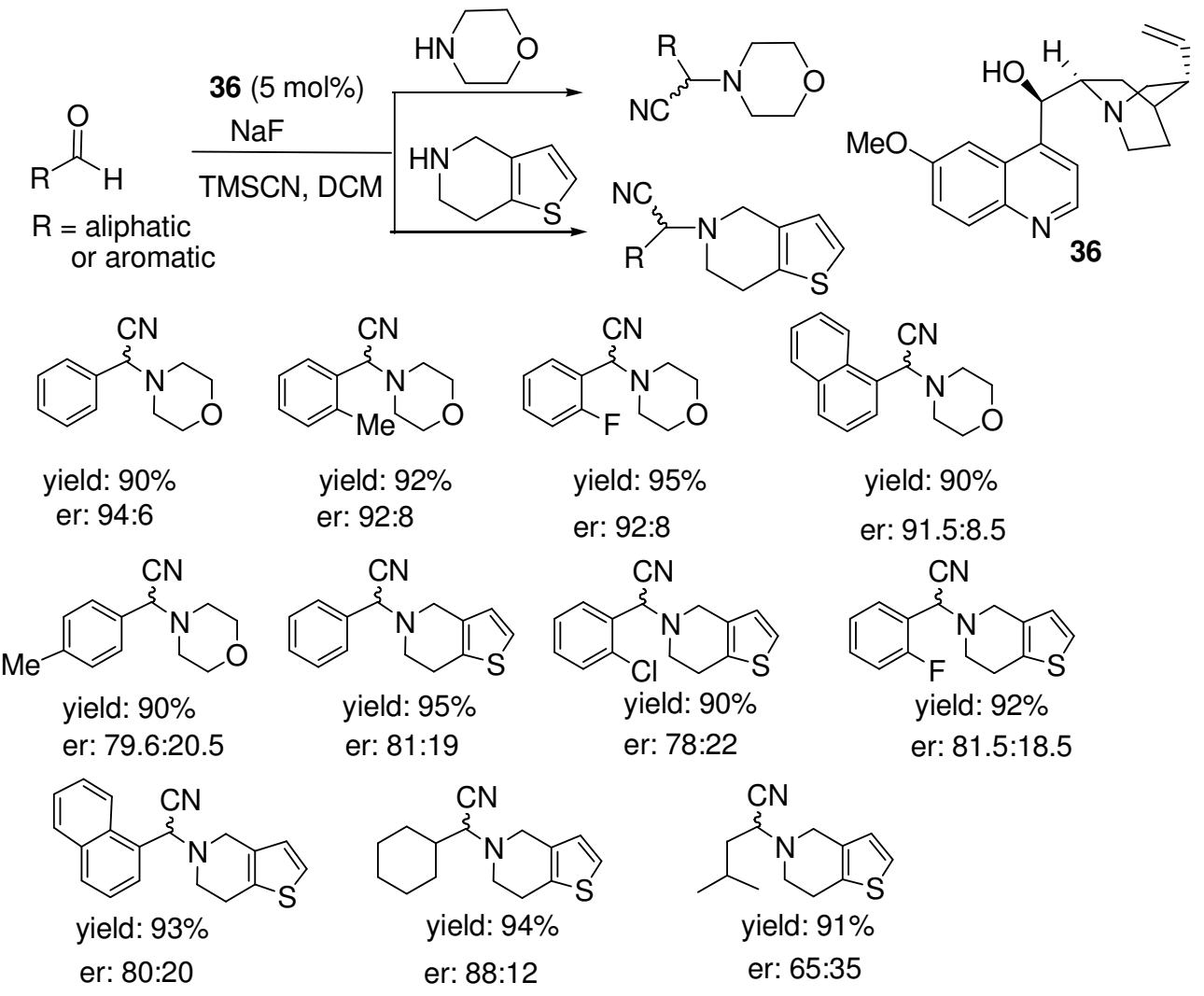

\section{Scheme 36}




\subsection{Phase-transfer-catalyzed reactions}

Phase transfer catalysis (PTC) is one of the most important and useful methods in synthetic organic chemistry because of its preparative advantages, such as simple reaction procedures, mild conditions, inexpensive and environmentally friendly reagents, and the ease in scaling-up the reaction. An asymmetric version of PTC utilizing chiral phase-transfer catalysts is a highly attractive method in terms of atom economy. ${ }^{71,72}$ In 2006, the Ooi group devised the phasetransfer-catalyzed asymmetric cyanation of $\mathrm{N}$-arylsulfonyl aldimines using aqueous potassium cyanide $(\mathrm{KCN})$ as a cyanide source through the molecular design of a chiral quaternary ammonium salt bearing a stereochemically defined tetranaphthyl backbone. ${ }^{73}$ The next year, the same group achieved a highly efficient, catalytic enantioselective synthesis of $N$-arylsulfonyl $\alpha$ amino nitriles from the corresponding $\alpha$-amido sulfones under toluene-aqueous potassium cyanide biphasic conditions using chiral quaternary ammonium iodide $(R, R, R)-\mathbf{3 7}$ as an effective phase-transfer catalyst (Scheme 37). ${ }^{74}$ This Strecker synthesis involving the in situ generation of the reactive $N$-sulfonyl imines was advantageous for the cyanation of the substrates having primary and secondary alkyl substituents.

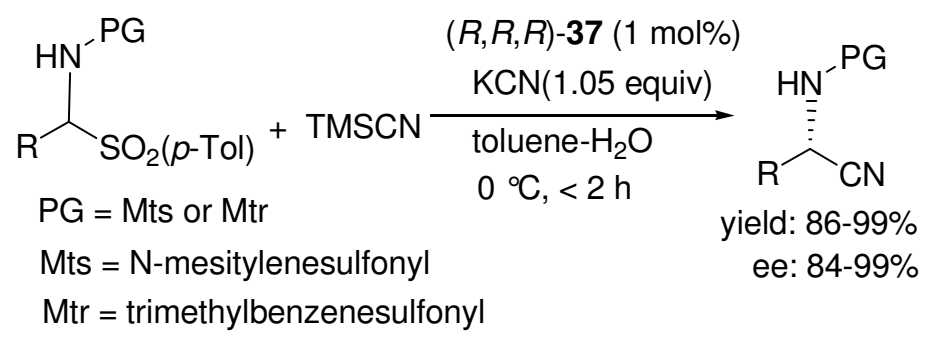

\begin{tabular}{llll}
\hline $\mathrm{R}$ & $\mathrm{PG}$ & Yield (\%) & $\mathrm{Ee} \mathrm{( \% )}$ \\
\hline $\mathrm{C}-\mathrm{Hex}$ & $\mathrm{Mts}$ & 99 & 97 \\
$\mathrm{PhCH}$ & $\mathrm{Mts}$ & 93 & 85 \\
$\mathrm{Ph}\left(\mathrm{CH}_{2}\right)_{2}$ & $\mathrm{Mts}$ & 99 & 94 \\
$\left(\mathrm{CH}_{3}\right)_{2} \mathrm{CHCH}_{2}$ & $\mathrm{Mts}$ & 99 & 98 \\
$\mathrm{CH}_{3}\left(\mathrm{CH}_{2}\right)_{5} \mathrm{CH}_{2}$ & $\mathrm{Mts}$ & 99 & 98 \\
$\mathrm{Cbz}-\mathrm{-}-\mathrm{S}-$ & $\mathrm{Mts}$ & 98 & 96 \\
$\mathrm{Ph}\left(\mathrm{CH}_{2}\right)_{2}$ & $\mathrm{Mtr}$ & 98 & 96 \\
$\left(\mathrm{CH}_{3}\right)_{2} \mathrm{CHCH}_{2}$ & $\mathrm{Mtr}$ & 99 & 93 \\
$\mathrm{CH}_{3}\left(\mathrm{CH}_{2}\right)_{5} \mathrm{CH}_{2}$ & $\mathrm{Mtr}$ & 96 & 89 \\
$\mathrm{PhCH}_{2}$ & $\mathrm{Mtr}$ & 86 & 86
\end{tabular}

\section{Scheme 37}

The Strecker synthesis is one of the most facile methods to access racemic $\alpha$-amino acids. However, feasible catalytic asymmetric Strecker reactions for the large-scale production of enantioenriched $\alpha$-amino acids are rare. Last year, Yan et al. reported a scalable catalytic 
asymmetric Strecker reaction that used an accessible chiral variant of oligoethylene glycol as the catalyst and KCN to generate a chiral cyanide anion. ${ }^{75}$ Various $\alpha$-amido sulfone substrates (alkyl, aryl and heteroaryl) can be transformed into the optically enriched Strecker products, $\alpha$ aminonitriles, with excellent yields and enantioselectivities (Scheme 38). Moreover, the robust nature of the catalyst enables a one-pot synthesis of enantiomerically pure $\alpha$-amino acids starting from $\alpha$-amido sulfones and simple catalyst recycling (Scheme 39). These features could make this protocol easily adaptable to the practical synthesis of unnatural $\alpha$-amino acids. The reaction mechanism was shown in Scheme 40.

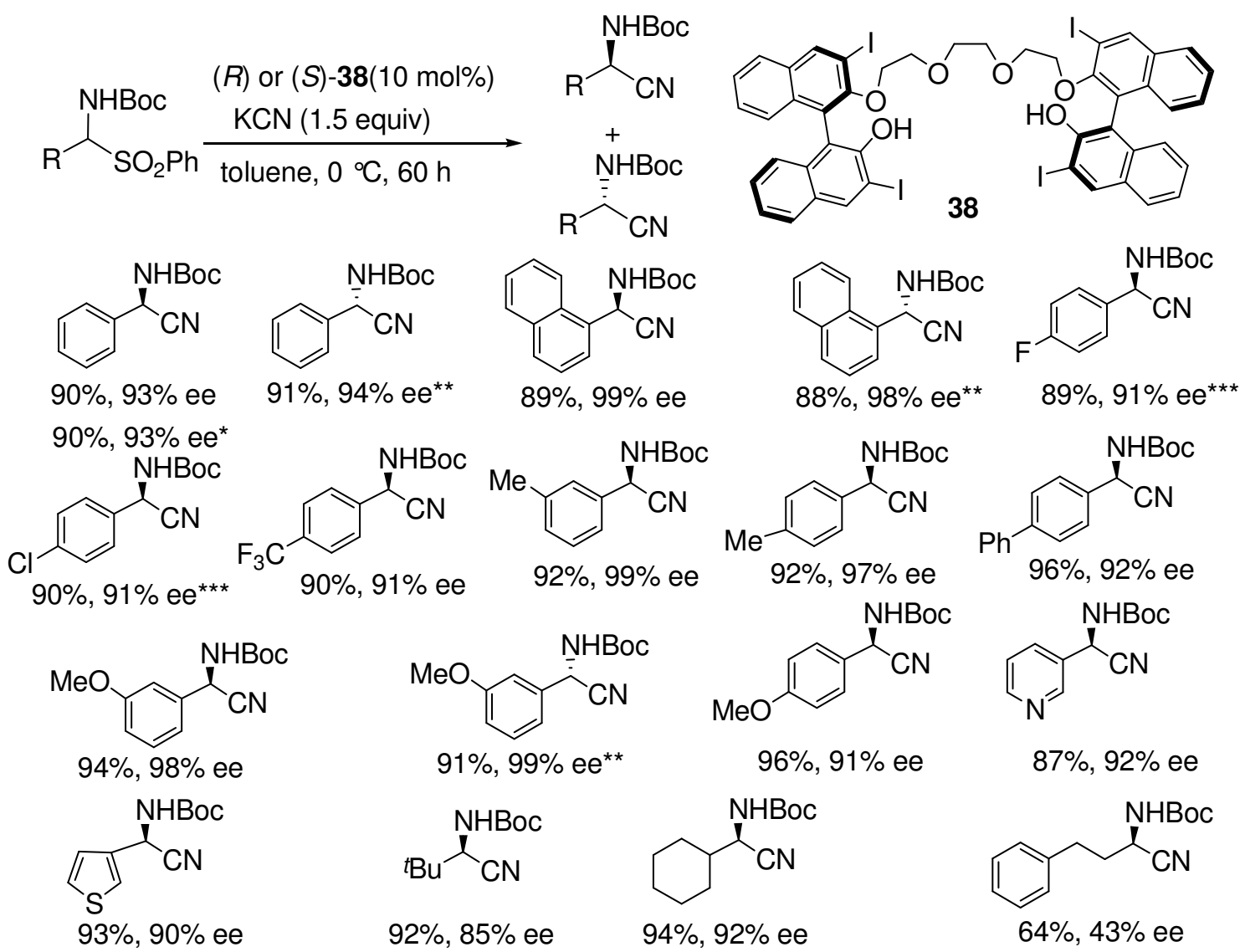

Unless otherwise indicated, the reactions were carried out with 4 (0.1-0.5 mmol), 1.05 equiv. of $\mathrm{KCN}$, and $(R)-38$ catalyst (10 mol\%) in toluene at $0{ }^{\circ} \mathrm{C}$. ${ }^{*}$ Two equivalents of $\mathrm{KCN}$ were used.

${ }^{* *}(S)-38$ catalyst was used. ${ }^{* *}$ The reaction was carried out using $20 \mathrm{~mol} \%$ of catalyst at $-20^{\circ} \mathrm{C}$ for $84 \mathrm{~h}$.

\section{Scheme 38}




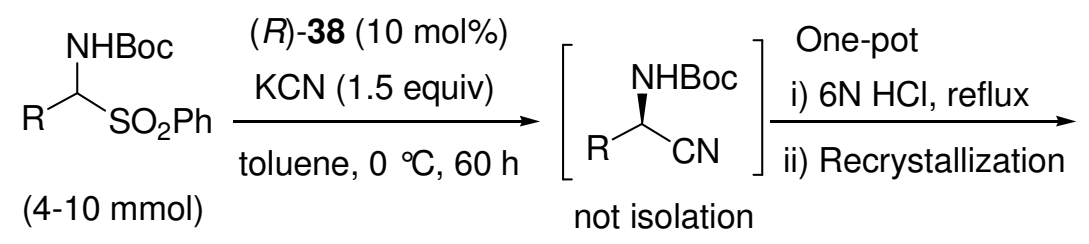

Unnatural $D$-amino acids<smiles>N#C[C@H](N)c1cccc2ccccc12</smiles>
$65 \%$, > $99 \%$ ee $55 \%$, > $99 \%$ ee<smiles>COc1cccc([C@H](N)C#N)c1</smiles><smiles>CC(C)(C)[C@H](N)[14CH2]Cl</smiles>
$65 \%$, > $99 \%$ ee $\quad 54 \%$, > $99 \%$ ee

(R)-38

Organic phase

Aqueous phase

$\overbrace{\mathrm{CN}}^{\mathrm{NH}_{2} \cdot \mathrm{HCl}}$

\section{Scheme 39}
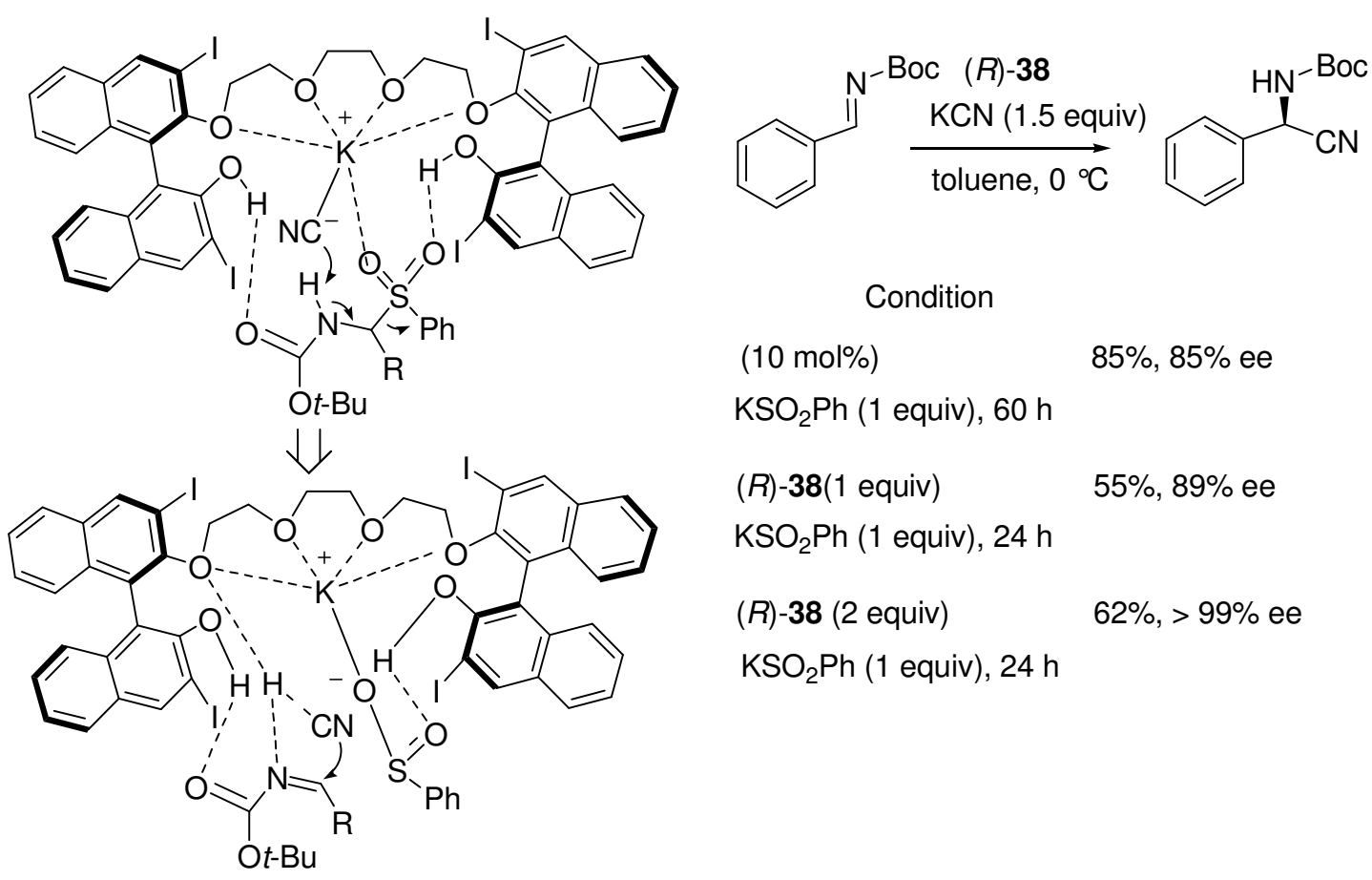

\section{Condition}

(10 mol\%)

$85 \%, 85 \%$ ee

$\mathrm{KSO}_{2} \mathrm{Ph}$ (1 equiv), $60 \mathrm{~h}$

(R)-38(1 equiv)

$55 \%, 89 \%$ ee

$\mathrm{KSO}_{2} \mathrm{Ph}$ (1 equiv), $24 \mathrm{~h}$

( $R$ )-38 (2 equiv)

$62 \%,>99 \%$ ee

$\mathrm{KSO}_{2} \mathrm{Ph}$ (1 equiv), $24 \mathrm{~h}$

\section{Scheme 40}

\subsection{Reactions catalysed by urea and thiourea derivatives}

Molecules containing functions with urea or thiourea moieties are known to be able to form double hydrogen bonds with the substrates, thereby activating or coordinating the substrates or even with both these functions acting in a synergetic manner. ${ }^{76}$ During the last few decades many chiral urea and thiourea derived catalysts have been developed for different enantioselective reactions. In general, thiourea derivatives are more popular in this field than urea derivative. Possibly the formation of stronger intermolecular hydrogen bonds (in comparison to thiourea analogues) between two molecules of urea leads to the decreasing of "free NH" groups which are 
responsible for the activation and coordination of substrates. Such interactions between urea molecules are well-known and described in literature. ${ }^{77}$

4.3.1 Urea derivatives. In 2011, Wang, Zhou et al. developed a general method for the catalytic asymmetric Strecker reaction of both $\alpha-\mathrm{CF}_{2} \mathrm{H}$ and $\alpha-\mathrm{CF}_{3}$ ketoimines and TMSCN, which was carried out in air using the readily available bifunctional ureas derivative catalyst 39 (Scheme 41). ${ }^{78}$ A remarkable fluorine effect on the reactivity and selectivity was observed and discussed. Based on the theoretical calculations and experimental data, a new recognition model of (thio)urea catalyst and $\alpha-\mathrm{CF}_{2} \mathrm{H}$ - or $\mathrm{CF}_{3}$-substituted ketoimines was proposed.

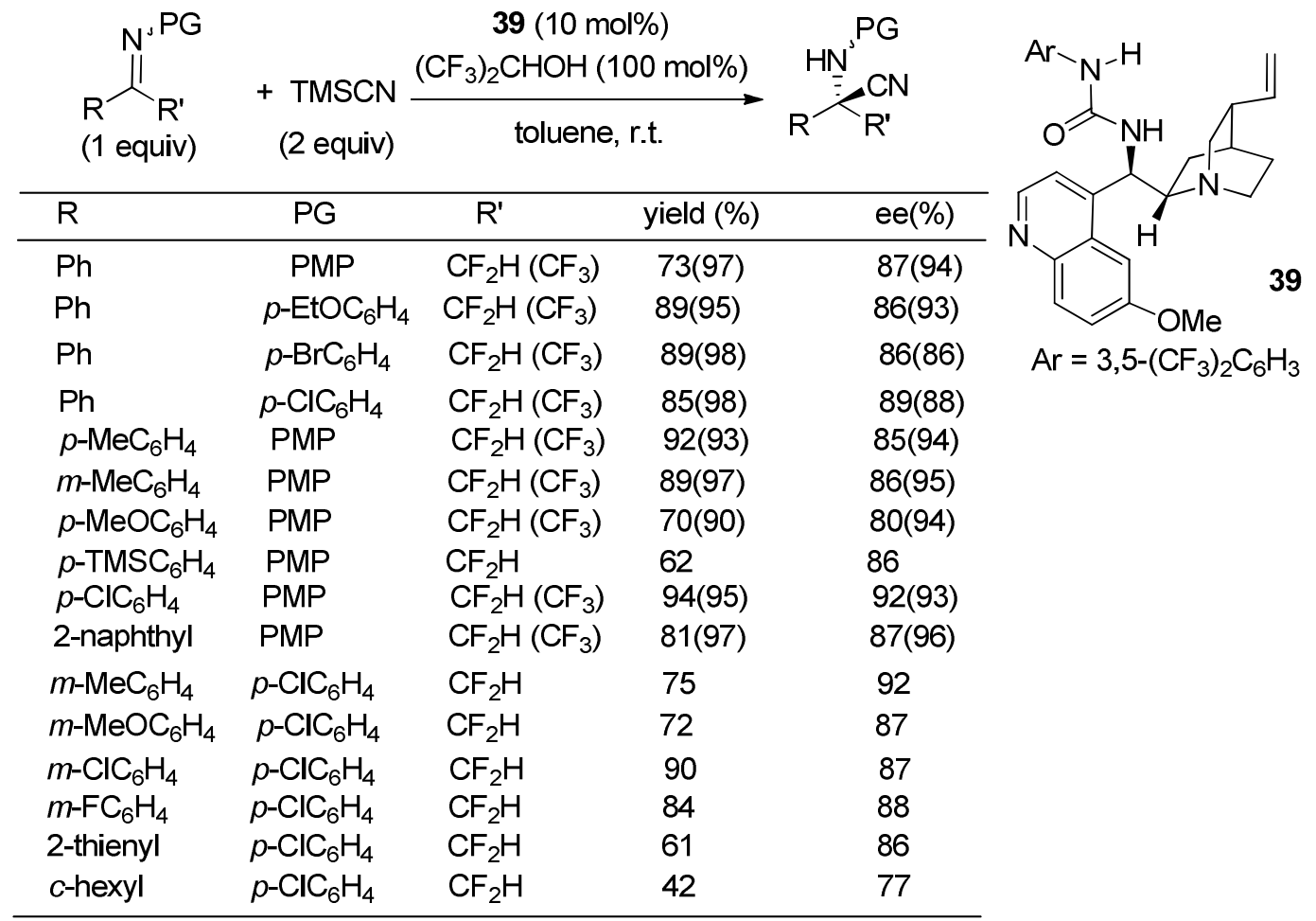

\section{Scheme 41}

4.3.2 Thiourea derivatives. The first application of chiral thiourea organocatalysts for enantioselective Strecker reaction of HCN with imines was reported by Jacobsen et al. in $1998 .{ }^{41}$ They demonstrated that thiourea-based derivative could stereoselectively catalyze the Strecker reaction. In 2007, Pan and List developed the organocatalytic asymmetric three-component Strecker reaction, the urea-catalyzed acylcyanation of in situ generated imines. ${ }^{79}$ Different $\alpha$ amido nitriles were formed in excellent yields and enantioselectivities from aldehydes, amines, and acyl cyanides in the presence of Jacobsen's thiourea catalyst 40 (Scheme 42). Despite its obvious use for the synthesis of $\alpha$-amino acids and their derivatives, the reaction might find use in diversity oriented synthesis and medicinal chemistry. 


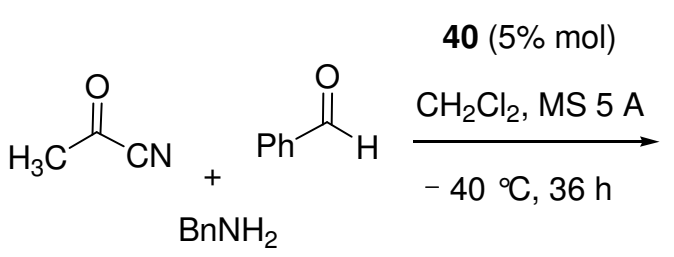

\section{Scheme 42}

Last year, Ma et al. developed the highly efficient asymmetric Strecker reaction of cyclic ketimines using simple cinchona alkaloid-based thioureas $\mathbf{4 1}$ and $\mathbf{4 2}$ as the chiral catalysts with as low as $1 \mathrm{~mol} \%$ loading under mild reaction conditions (Scheme 43) ${ }^{80}$ The major advantage of this process is that both enantiomers of $\alpha$-amino nitriles can be accessed in good to excellent yields (91-99\%) and enantioselectivities (90-97\% ee). Moreover, the Strecker reaction serves as a key step in the asymmetric preparation of the anti-HIV drug DPC 083, thus illustrating the synthetic utility of the Strecker adducts (Scheme 43). Regarding the mechanism of the reaction, it was suggested that both thiourea and tertiary amine moieties of the organocatalyst could play a significant role in controlling the enantioselectivity of the addition reaction. Trifluoromethylquinazolin-2 $(1 H)$-ones coordinate to the thiourea moiety through hydrogen bonding interaction, whereas the $\mathrm{HCN}$ generated in situ from TMSCN and water seems to be more likely to act as the nucleophile activated by a Lewis basic tertiary amine moiety (Scheme 44). In the presence of amino-thiourea catalyst $\mathbf{4 1}$, the nucleophilic cyanide attacks the $\mathrm{C}=\mathrm{N}$ double bond from the $R e$ face, leading to the formation of the adduct with $R$-configuration. The attack of cyanide from the $S i$ face was restricted by the cinchona alkaloid scaffold of the catalyst.

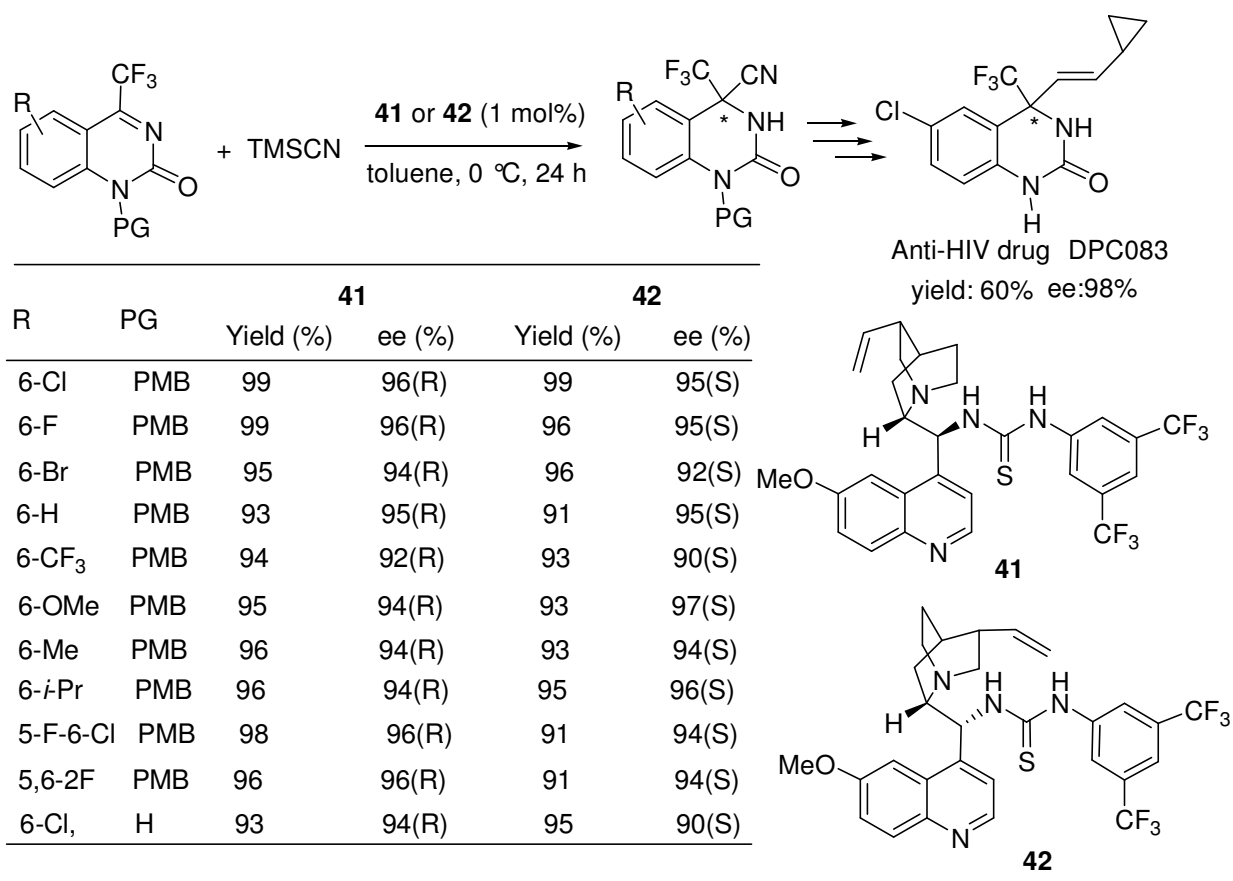

\section{Scheme 43}




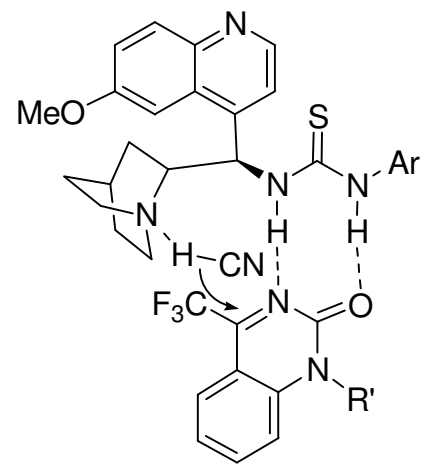

\section{Scheme 44}

In 2012, Shao and Tian reported that a range of $3 H$-indoles and $2 H-1$,4-benzothiazines smoothly undergo asymmetric Strecker reaction with ethyl cyanoformate in the presence of a Cinchona alkaloid-based thiourea catalyst $\mathbf{4 3}$ and $\mathbf{4 4}$ at $10{ }^{\circ} \mathrm{C}$ to give structurally diverse nitrogen-containing heterocycles in good to excellent yields and with excellent ee (Scheme 45). ${ }^{81}$ Furthermore, to the best of our knowledge, this method also represents the first enantioselective organocatalyzed Strecker reaction with $N$-Boc-ketimines as electrophiles.

In 2013, Liu and Zhou reported the catalytic asymmetric cyanation of $N$-Boc ketoimines, which enables highly enantioselective synthesis of oxindole based $\alpha$-amino nitriles with cinchona alkaloid-derived thiourea as catalyst 45 (Scheme 46). ${ }^{82}$ An unprecedented tandem azaWittig/Strecker reaction is also developed, emerging as a promising strategy for the catalytic asymmetric cyanation of ketoimines formed in situ from achiral ketones. Following this work, Wang also developed the asymmetric Strecker-type reaction between azomethine imines and TMSCN catalyzed by $1 \mathrm{~mol} \%$ of a cinchona alkaloid-derived thiourea $\mathbf{4 6}$ bearing multiple hydrogen-bonding donors to afford optically active amino nitriles in good to excellent yields and enantioselectivities (Scheme 47). ${ }^{83}$ 


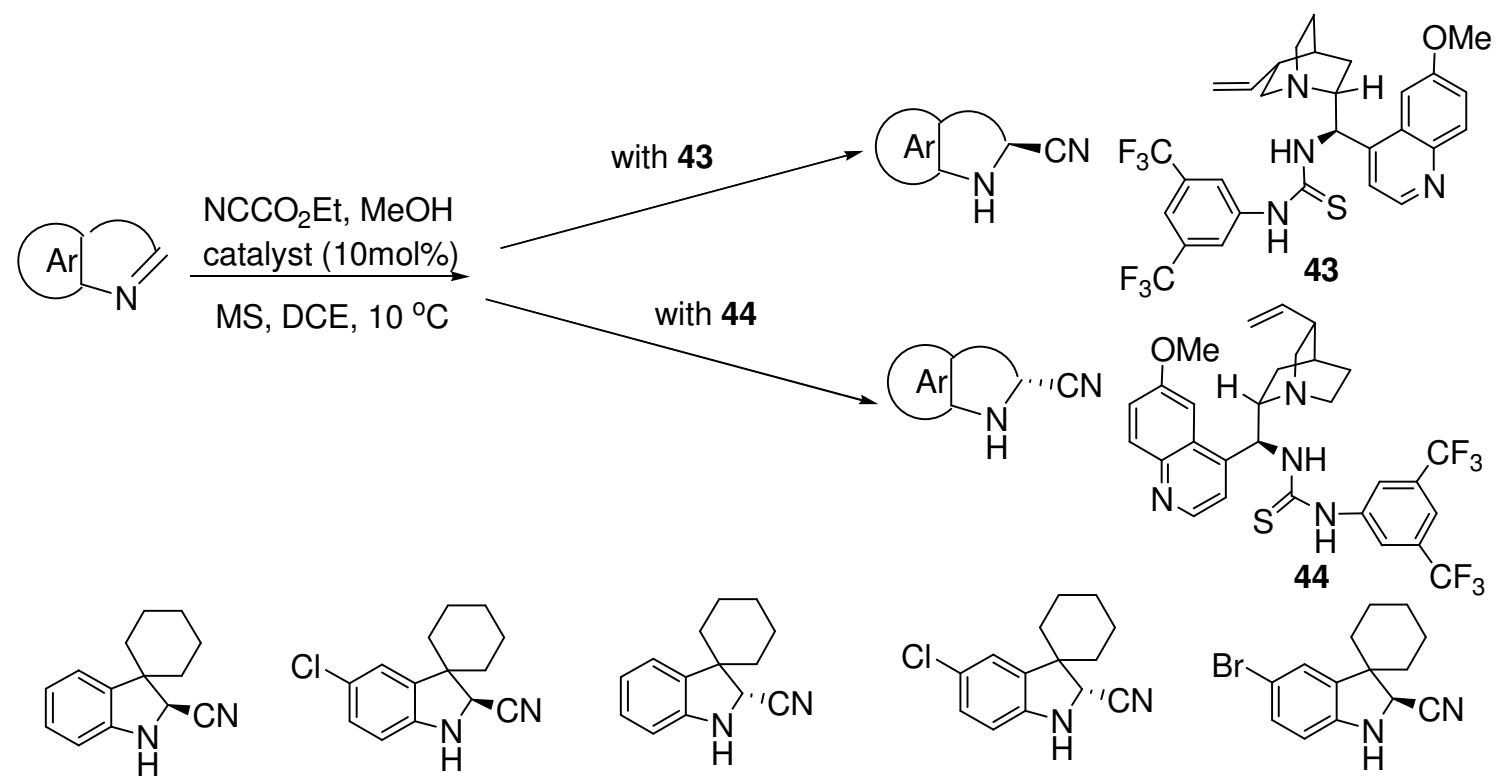

99\% yield; $96 \%$ ee $73 \%$ yield; $97 \%$ ee $99 \%$ yield; $97 \%$ ee $\quad 80 \%$ yield; $97 \%$ ee $83 \%$ yield; $98 \%$ ee<smiles>Cc1ccc2c(c1)C1(CCCCC1)[C@H](C#N)N2</smiles>

99\% yield; $97 \%$ ee $90 \%$ yield; $96 \%$ ee

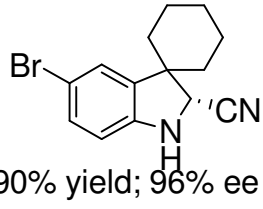<smiles>Cc1cc(C)c2c(c1)NC(C#N)C21CCCCC1</smiles>
$99 \%$ yield; $97 \%$ ee<smiles>Cc1ccc2c(c1)C1(CCCCC1)C[C@H]2C#N</smiles>

$99 \%$ yield: $98 \%$ ee

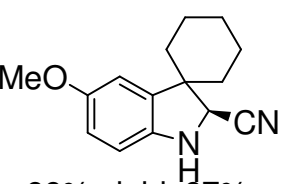

$99 \%$ yield; $97 \%$ ee $99 \%$ yield; $98 \%$ ee<smiles>COc1ccc2c(c1)C1(CCCCC1)C(C#N)N2</smiles>

99\% yield; $98 \%$ ee<smiles>N#CC1(C#N)Nc2ccccc2C12CCCC2</smiles>

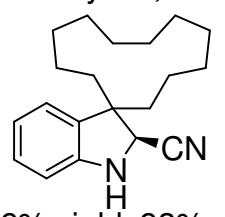<smiles>N#CC1Nc2ccc3ccccc3c2C12CCCCC2</smiles>

$99 \%$ yield; $95 \%$ ee

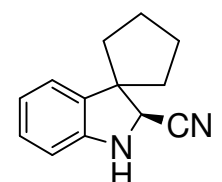

93\% yield; $92 \%$ ee $99 \%$ yield; $97 \%$ ee

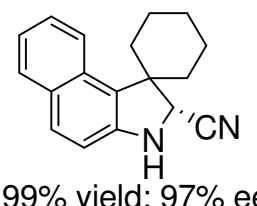

$83 \%$ yield; $98 \%$ ee $\quad 99 \%$ yield; $93 \%$ ee<smiles>N#C[C@H]1Nc2ccccc2C12CCOCC2</smiles>

$99 \%$ yield; $91 \%$ ee $\quad 99 \%$ yield: $94 \%$ ee

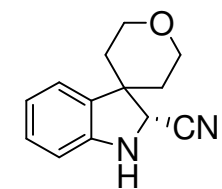

$99 \%$ yield; $98 \%$ ee<smiles>N#CC1Nc2ccc(Br)cc2C12CCN(C(=O)O)CC2</smiles>

$85 \%$ yield; $97 \%$ ee<smiles>CC1(C)Sc2ccccc2NC1C#N</smiles>

90\% yield; $94 \%$ ee<smiles></smiles>

$98 \%$ yield; $96 \%$ ee<smiles>N#CC1Nc2ccccc2SC12CCCCC2</smiles>

99\% yield; $94 \%$ ee<smiles>N#CC1Nc2ccc(Br)cc2C12CCN(C(=O)O)CC2</smiles>

$79 \%$ yield; $97 \%$ ee<smiles>CC1(C)Sc2ccccc2NC1C#N</smiles>

$98 \%$ yield; $97 \%$ ee<smiles>N#CC1(C(Br)(Br)Br)Nc2cccc3c2C31C(Br)(Br)Br</smiles>

95\% yield; $98 \%$ ee<smiles>N#CC1(C#N)Nc2ccccc2S1</smiles>

99\% yield; $97 \%$ ee

\section{Scheme 45}




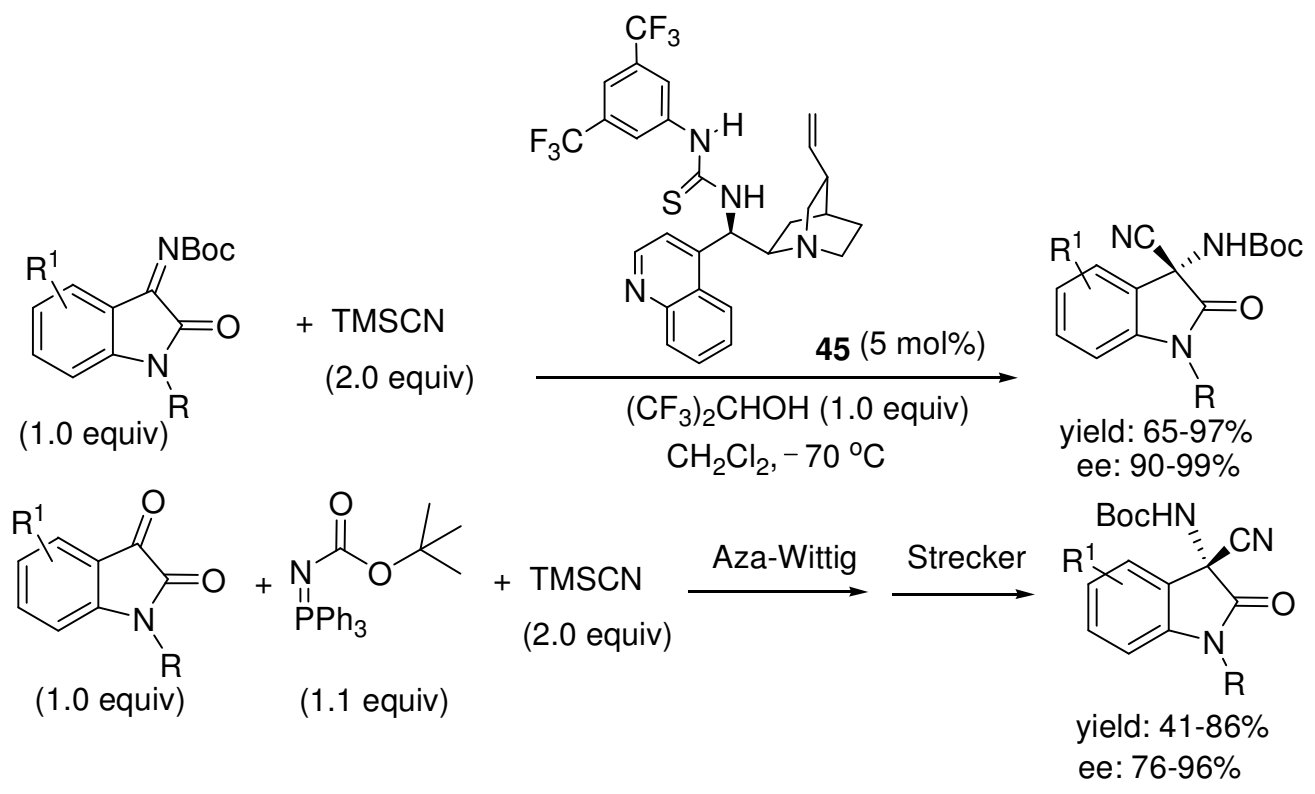

\section{Scheme 46}

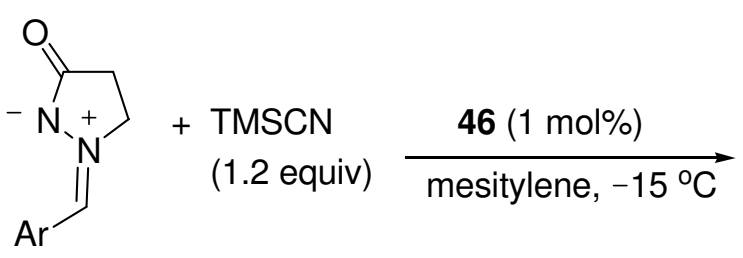

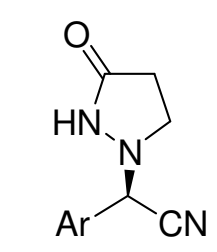

yield: up to $99 \%$

ee: up to $97 \%$<smiles>C=CC1CN2CCC1C(C[C@H](NC(N)=S)c1ccnc3ccc(OC)cc13)C2</smiles><smiles>O[C@H](C[PbH])c1ccccc1</smiles>

\section{Scheme 47}

Recently, Yan, Wang et al. have developed a very practical method for the asymmetric synthesis of 3-amino-3-cyanooxindoles through the addition of TMSCN to isatin-derived $N$-Bocketimines with a quinine-derived thiourea catalyst $\mathbf{4 3}$ (Scheme 48 ). ${ }^{84}$ The nucleophilic addition of trimethylsilyl cyanide to $\mathrm{N}$-Boc-ketimines affords 3-amino-3-cyanooxindoles in good to excellent yields (78-98\%) and very good enantioselectivities (up to 94\%). In addition, a variety of ketimines bearing electron-withdrawing and electron-donating substituents at different positions on the aromatic ring were tested and afforded the expected reactions products in good yields and enantioselectivities. The absolute configuration of product was ascertained as $(R)$ on the basis of an X-ray crystal structure analysis. They suggested a possible mechanism for the addition of TMSCN to $N$-Boc-ketimines derived from $N$-methylisatins. As shown in Scheme 49, similar to the model suggested by the Feng group, the catalyst displays the dual function of 
activating both reaction partners. ${ }^{85}$ The tertiary amine of the catalyst promotes the formation of $\mathrm{HCN}$, and then, through coordination, holds it in close proximity, while the thiourea moiety binds and activates the ketimine through hydrogen bonds. Following an enantioselective addition of $\mathrm{CN}$ to ketimine from the $R e$-face, the $(R)$ configured product was obtained.

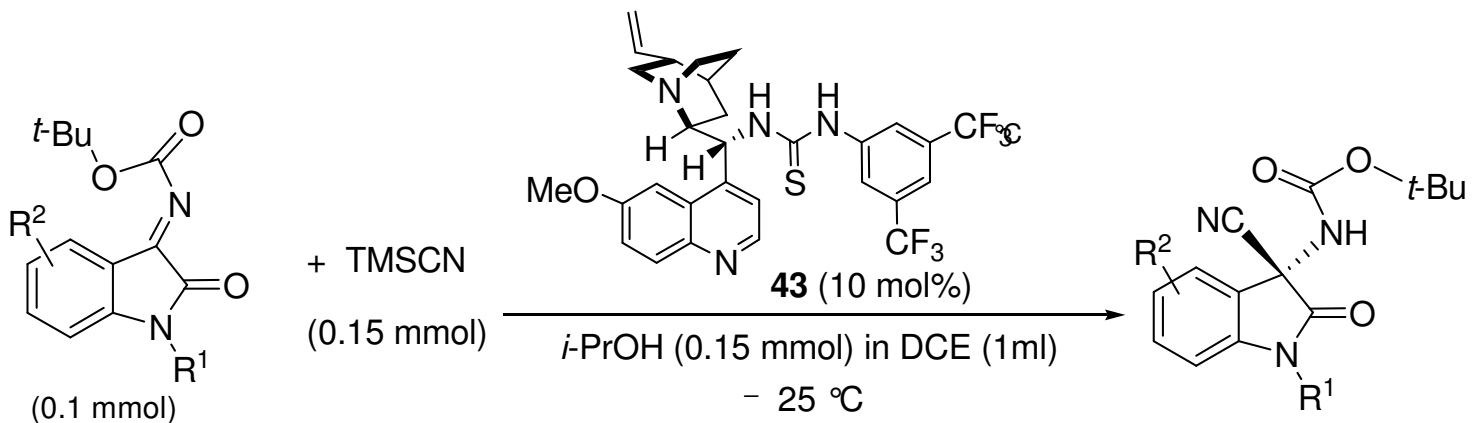<smiles>CN1C(=O)C(C#N)(C(C)(C)C)c2ccccc21</smiles><smiles>CN1C(=O)C(C)(C(C)(C)C)c2c(Cl)cccc21</smiles><smiles>CN1C(=O)C(C)(C(C)(C)C)c2c(Br)cccc21</smiles><smiles>CN1C(=O)[C@](N)(NC(C)(C)C)c2cc([N+](=O)[O-])ccc21</smiles><smiles>CN1C(=O)[C@](C)(NC(=O)OCc2ccccc2)c2cc(Br)ccc21</smiles>

$18 \mathrm{~h}, 96 \%$ yield $20 \mathrm{~h}, 97 \%$ yield

$24 \mathrm{~h}, 78 \%$ yield $10 \mathrm{~h}, 94 \%$ yield $16 \mathrm{~h}, 98 \%$ yield $93 \%$ ee $62 \%$ ee $60 \%$ ee $89 \%$ ee $92 \%$ ee

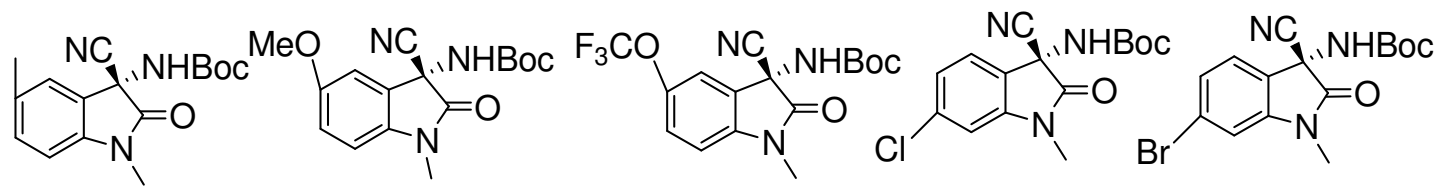
$22 \mathrm{~h}, 98 \%$ yield $30 \mathrm{~h}, 93 \%$ yield $18 \mathrm{~h}, 96 \%$ yield $10 \mathrm{~h}, 94 \%$ yield $16 \mathrm{~h}, 98 \%$ yield $90 \%$ ee

$$
93 \% \text { ee }
$$
$90 \%$ ee $93 \%$ ee<smiles>CN1C(=O)[C@](C#N)(NC(=O)OCc2ccccc2)c2cccc(F)c21</smiles>

$8 \mathrm{~h}, 98 \%$ yield $91 \%$ ee<smiles>CN1C(=O)[C@](C)(NC(=O)OC(C)(C)C)c2cc(Br)cc(Br)c21</smiles>

$18 \mathrm{~h}, 97 \%$ yield $87 \%$ ee<smiles>CN1C(=O)[C@](C)(NC(C)(C)C)c2cccc(Cl)c21</smiles>

$12 \mathrm{~h}, 98 \%$ yield $91 \%$ ee<smiles>C=CCN1C(=O)[C@@](C#N)(NC(=O)OC(C)(C)C)c2ccccc21</smiles>

$16 \mathrm{~h}, 96 \%$ yield $91 \%$ ee<smiles>CN1C(=O)[C@](C)(NC(=O)OC(C)(C)C)c2cccc(Br)c21</smiles>

$20 \mathrm{~h}, 98 \%$ yield $91 \%$ ee<smiles>CC(C)(C)OC(=O)N[C@]1(C#N)C(=O)N(C/C=C/c2ccccc2)c2ccccc21</smiles>

$16 \mathrm{~h}, 96 \%$ yield $92 \%$ ee $89 \%$ ee<smiles>Cc1cc(Br)cc2c1N(C)C(=O)[C@]2(C)N</smiles>

$16 \mathrm{~h}, 96 \%$ yield $86 \%$ ee<smiles>N#CC1(N)C(=O)N(C/C=C/c2ccc(Cl)c(Cl)c2)c2ccccc21</smiles>

\section{Scheme 48}




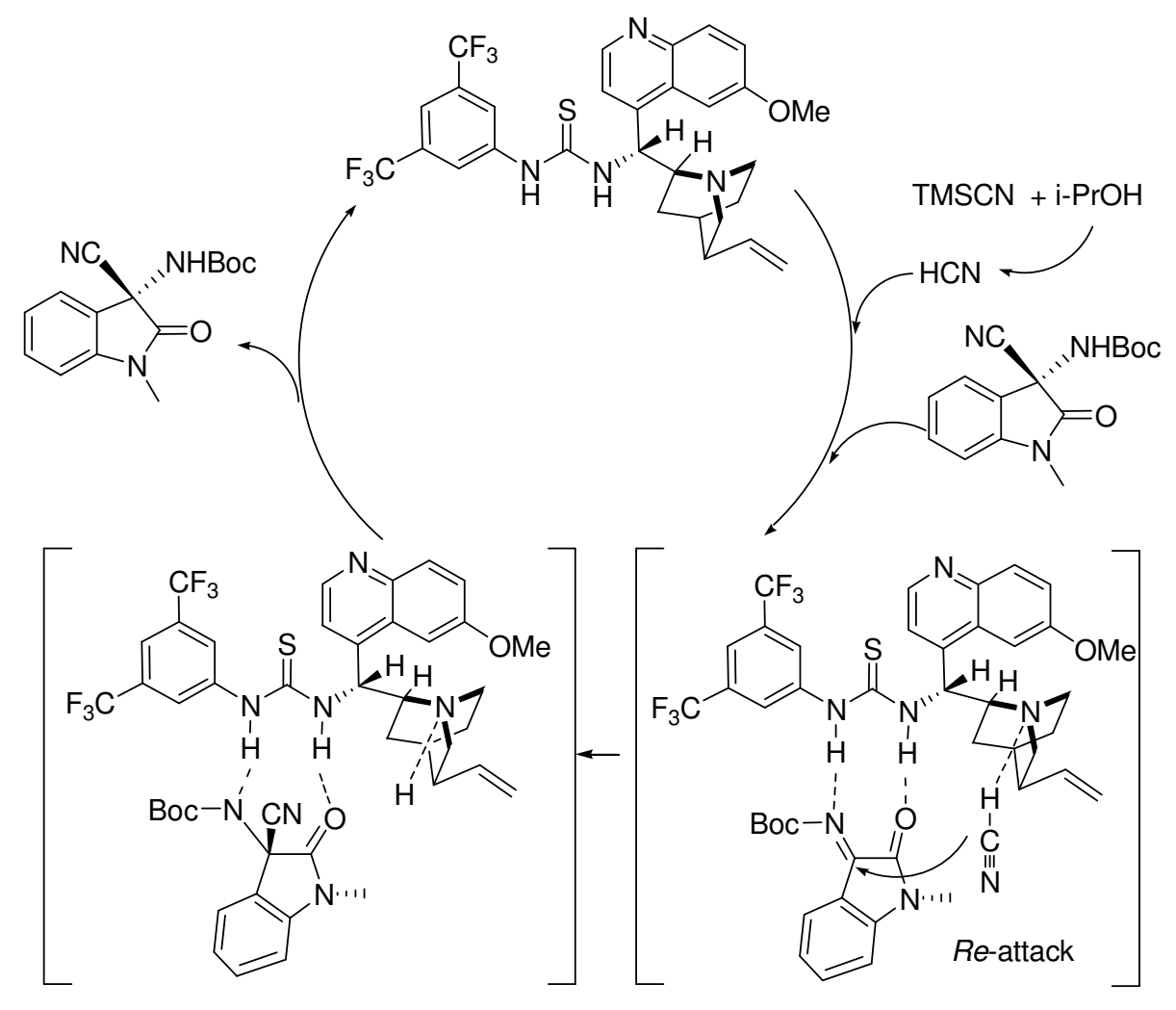

\section{Scheme 49}

\subsection{Reactions catalysed by chiral bisformamides}

In 2007, Feng's group showed C2-symmetric chiral bisformamides $\mathbf{4 7}$ to catalyze the asymmetric one-pot, three-component Strecker reaction, which produced the $\alpha$-amino nitriles in excellent yields (up to 99\%) with good enantioselectivities (up to $86 \%$ ee) (Scheme 50). ${ }^{86}$ Optically pure products could be obtained after a single recrystallization. A possible transition state has been proposed to explain the origin of asymmetric induction and reactivity according to the geometry of catalyst optimized at the B3LYP/6-31G(d) level and the absolute configuration of product.

In the following year, the group developed the one-pot three-component Strecker reaction with an aldehyde, 1,1-diphenylmethylamine, and TMSCN using trans-4-hydroxy-L-prolinederived $N, N^{\prime}$-dioxides $\mathbf{4 8}$ and used as efficient organocatalysts (Scheme 51 ) ${ }^{87}$ Both aromatic and aliphatic aldehydes were found to be suitable substrates. The corresponding $\alpha$-amino nitriles were obtained in high yields with up to $95 \%$ ee under mild conditions. Optically pure products could be obtained after a single recrystallization. The catalyst can be easily prepared from trans4-hydroxy-L-proline and a diamine in three steps. Based on the experimental results and the observed absolute configurations of the products, a possible transition state has been proposed to explain the origin of the asymmetric induction. 


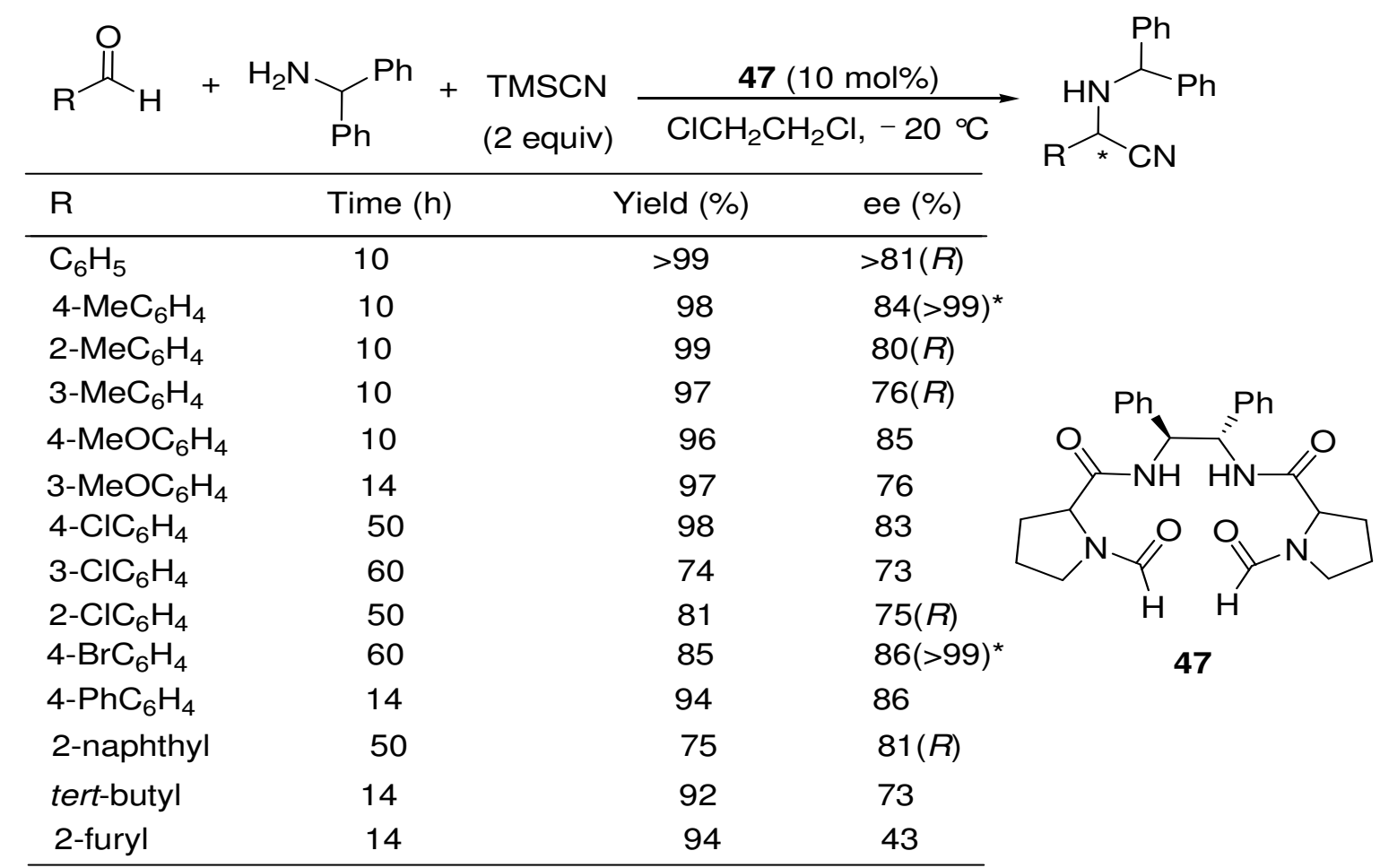

${ }^{*}$ After single recrystallization

\section{Scheme 50}

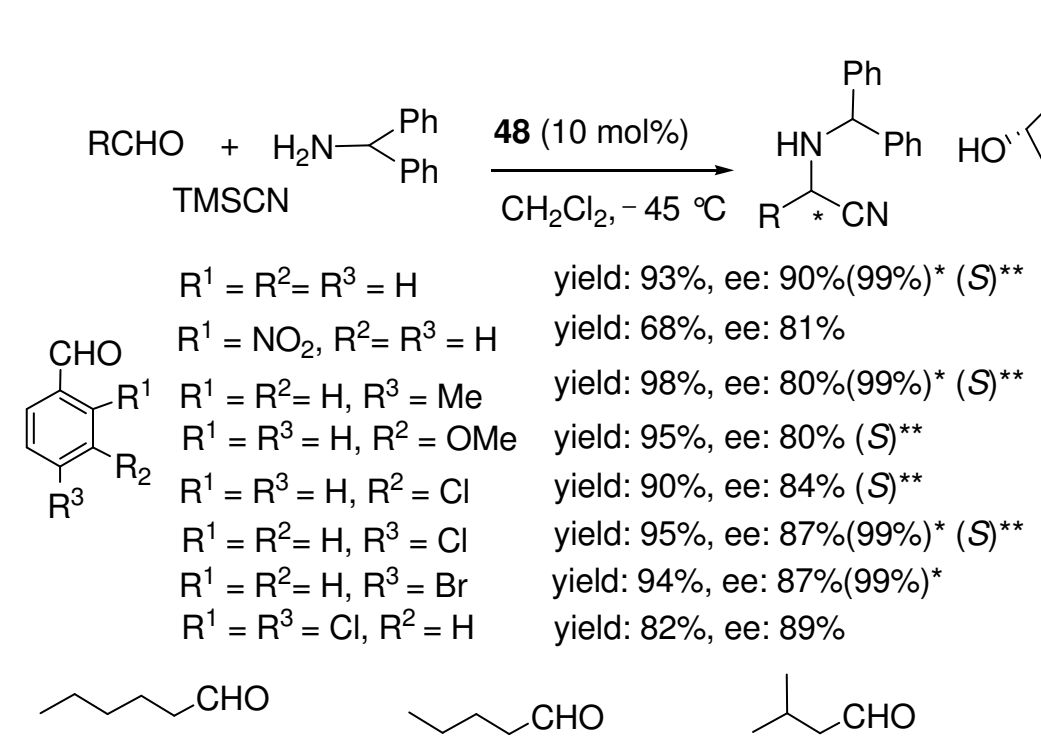

yield: $96 \%$, ee: $81 \%$<smiles>CCC(C=O)CC</smiles>

yield: $65 \%$, ee: $80 \%$

\begin{abstract}
yield: $95 \%$, ee: $90 \%$
\end{abstract}

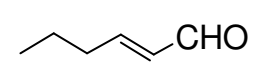

yield: $86 \%$, ee: $95 \% \quad$ yield: $93 \%$, ee: $80 \% \quad$ yield: $87 \%$, ee: $72 \%$

* after a single recrystallization; ** absolute configuration
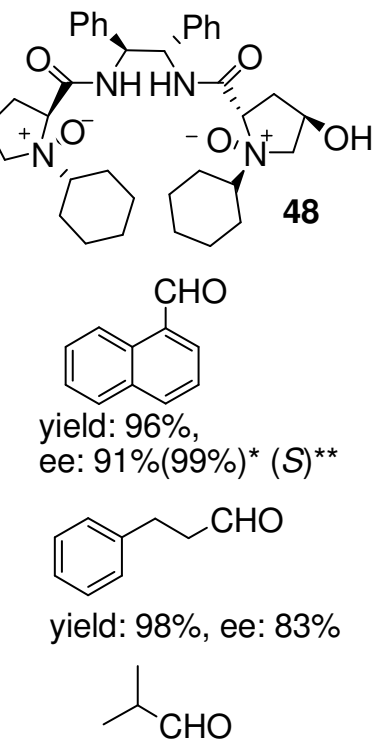

yield: $98 \%$, ee: $87 \%$

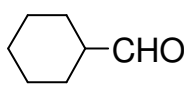

yield: $99 \%$, ee: $84 \%$

\section{Scheme 51}


In 2012, Khan et al. reported the recyclable chiral amide-based organocatalyst 49 is highly efficient for the catalysis of the asymmetric Strecker reaction of aromatic and aliphatic aldimines with ethyl cyanoformate as a source of cyanide. ${ }^{88}$ The chiral organocatalyst 49 could efficiently catalyze asymmetric Strecker reaction of various aromatic and aliphatic $N$-benzhydrylimines with ethyl cyanoformate as cyanide source with at $-10{ }^{\circ} \mathrm{C}$ to give a high yield $(95 \%)$ of $\alpha$ aminonitriles with excellent chiral induction (ee, up to $99 \%$ ) with the added advantage of recyclability (Scheme 52). Based on experimental observations a probable mechanism was proposed for this reaction. This protocol with catalyst 49 was extended for the synthesis of $(R)$ phenylalanine and pharmaceutically important drug intermediate $(R)$-3-phenylpropane-1,2diamine in high yield with high enantioselectivity (Scheme 53).
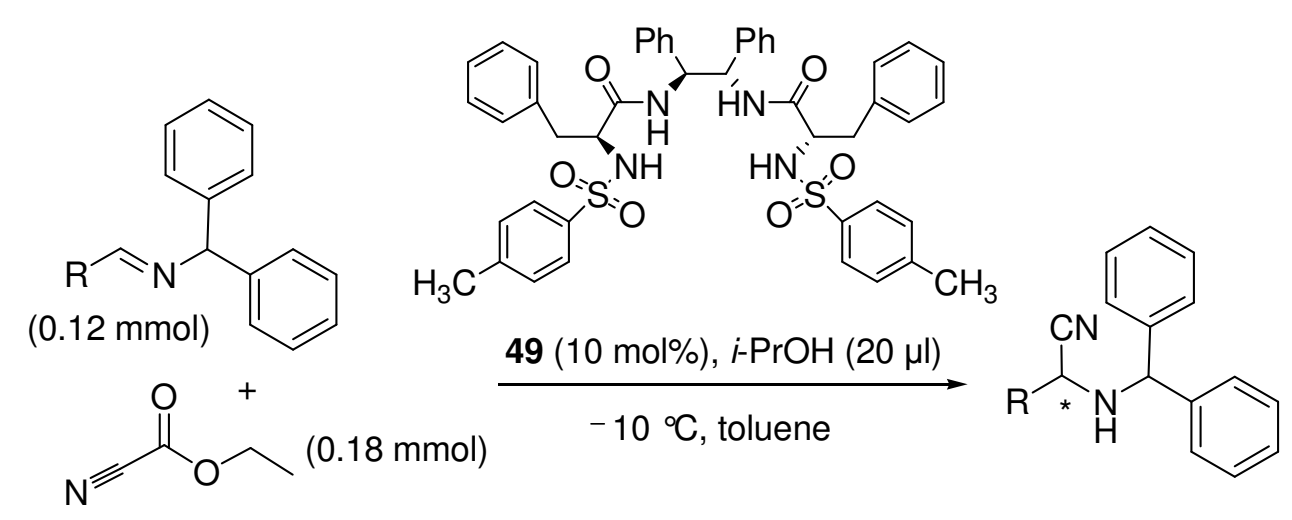

\begin{tabular}{lclllllc}
\hline $\mathrm{R}$ & Time $(\mathrm{h})$ & Yield (\%) & ee $(\%)$ & $\mathrm{R}$ & Time $(\mathrm{h})$ & Yield (\%) & ee (\%) \\
\hline $\mathrm{Ph}$ & 20 & 85 & $91(R)$ & 2-EtO- $\mathrm{C}_{6} \mathrm{H}_{4}$ & 20 & 75 & 86 \\
$2-\mathrm{Br}-\mathrm{C}_{6} \mathrm{H}_{4}$ & 24 & 92 & 96 & $2-{\mathrm{Me}-\mathrm{C}_{6} \mathrm{H}_{4}}$ & 20 & 79 & 74 \\
$2-\mathrm{NO}_{2}-\mathrm{C}_{6} \mathrm{H}_{4}$ & 24 & 95 & 99 & & & & \\
$2-\mathrm{F}-\mathrm{C}_{6} \mathrm{H}_{4}$ & 24 & 91 & 99 & tert-butyl & 20 & 88 & 95 \\
$2-\mathrm{Cl}_{6} \mathrm{C}_{6} \mathrm{H}_{4}$ & 24 & 90 & 92 & $\mathrm{Ph}-\mathrm{CH}_{2}$ & 20 & 90 & 93 \\
$2-\mathrm{MeO}-\mathrm{C}_{6} \mathrm{H}_{4}$ & 20 & 86 & 78 & isobutyl & 20 & 77 & 81 \\
$3-\mathrm{MeO}-\mathrm{C}_{6} \mathrm{H}_{4}$ & 20 & 85 & 65 & 3-pyridinyl & 20 & 70 & 60 \\
$4-\mathrm{MeO}-\mathrm{C}_{6} \mathrm{H}_{4}$ & 20 & 78 & 28 & 2-naphthyl & 24 & 74 & 85 \\
\hline
\end{tabular}

\section{Scheme 52}




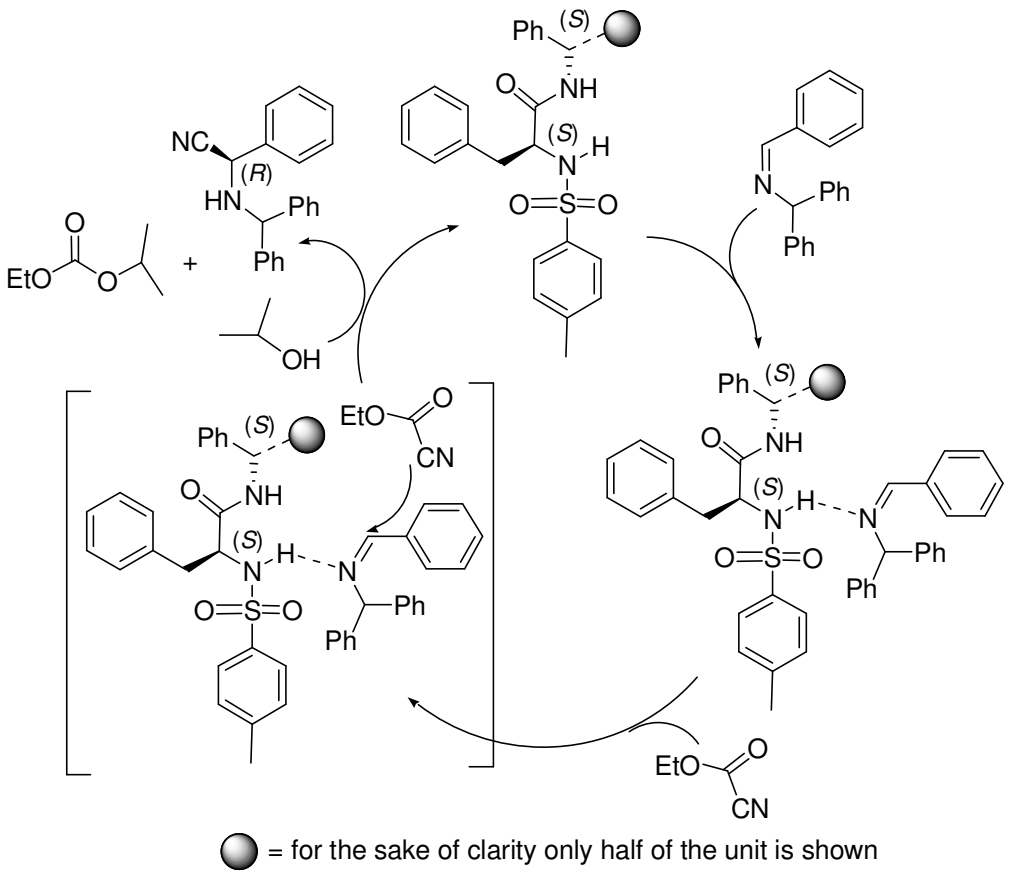

\section{Scheme 53}

\subsection{Reactions catalysed by chiral BINOL-phosphoric acids}

In 2010, Zhang et al. developed a general method for the one-pot, three-component Strecker reaction of ketones using chiral BINOL-phosphoric acids $\mathbf{5 0}$ and $\mathbf{5 1}$ as organocatalysts, and a series of $\alpha$-aminonitriles were obtained in good to excellent yields (79-99\%) (Schemes 54 and 55). ${ }^{89}$ A preliminary extension to a catalytic enantioselective three-component Strecker reaction of ketones (up to $40 \%$ ee) was also described.

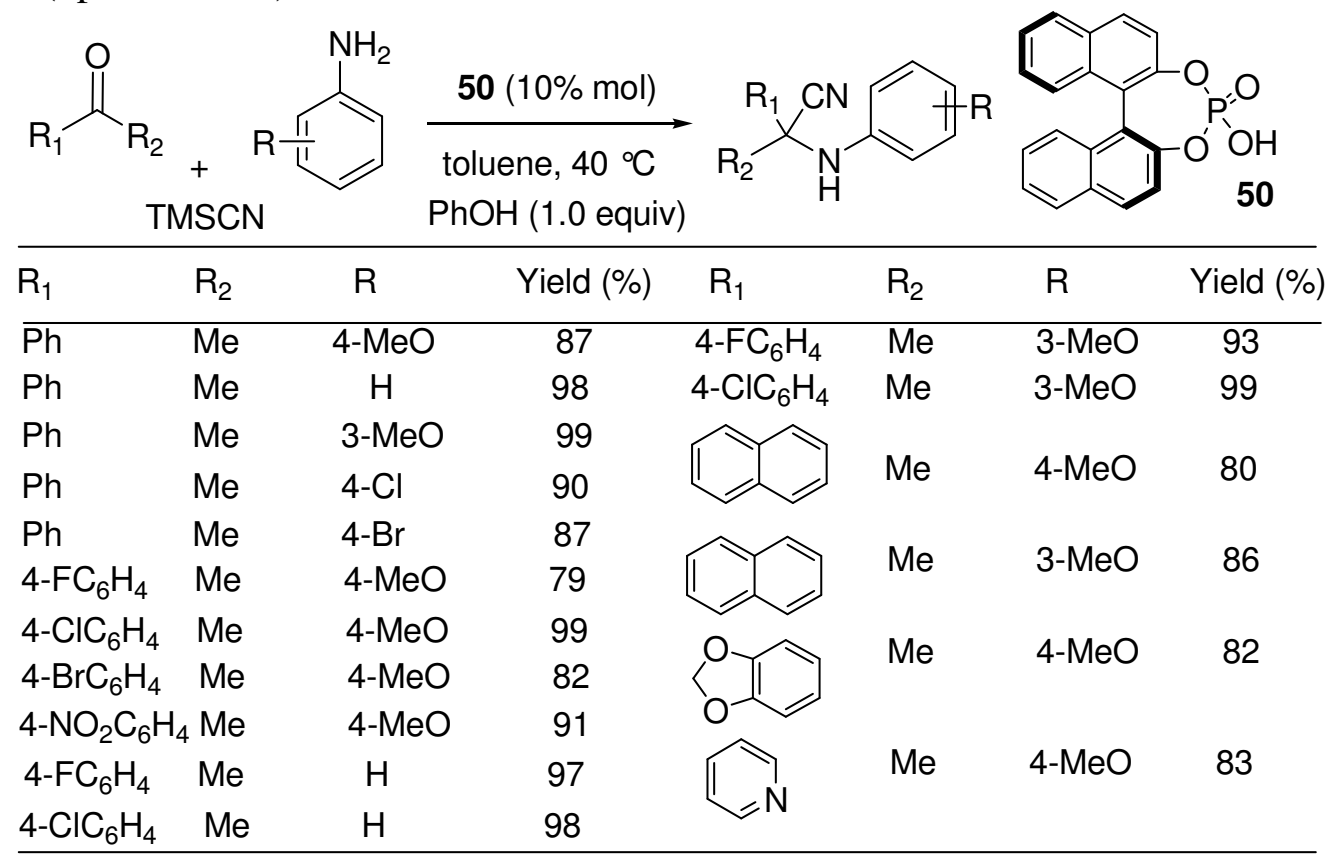

\section{Scheme 54}




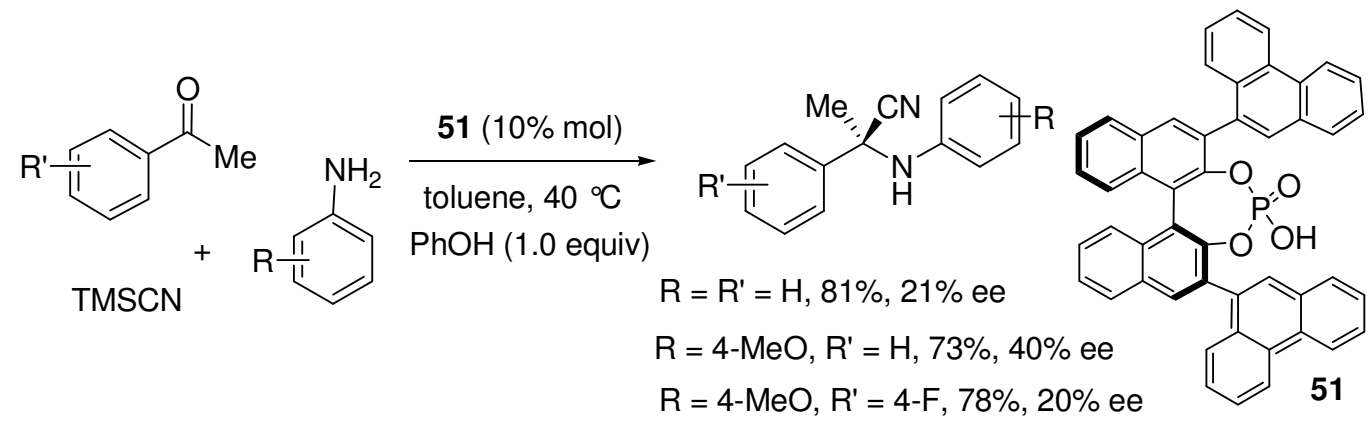

\section{Scheme 55}

\subsection{Reactions catalysed by chiral dicarboxylic acids}

In 2010, Hashimoto et al. reported a highly enantioselective imino aza-enamine reaction catalyzed by axially chiral dicarboxylic acid 52. The reaction was elaborated into a surrogate of the asymmetric Strecker reaction building on the fact that the $N, N$-dialkylhydrazone moiety can be easily converted into the cyanide moiety by treatment with peracid (Scheme 56) ${ }^{90}$

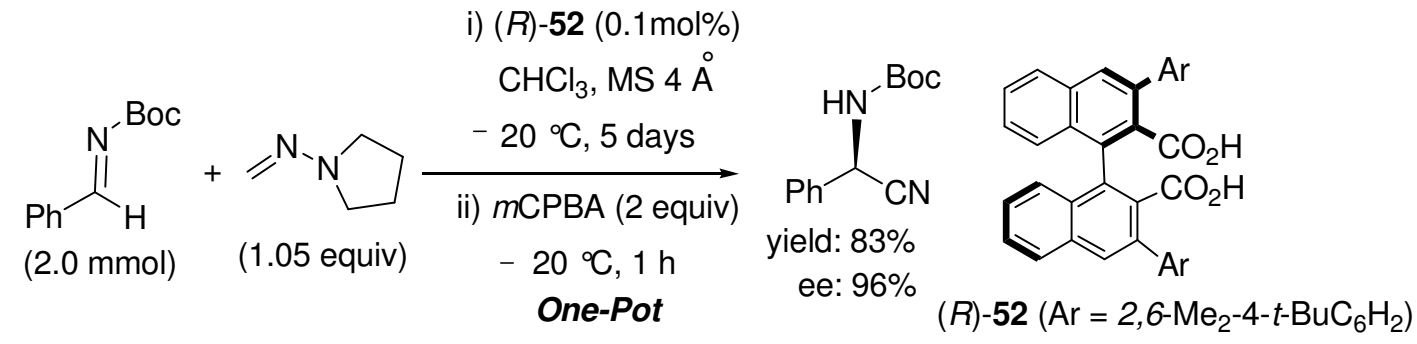

\section{Scheme 56}

\section{Conclusions}

The Strecker addition of cyanide to imines has become one of the most important carbon-carbon bond formation reactions, and the corresponding adducts of $\alpha$-amino nitriles can readily be converted into valuable building blocks in organic synthesis and pharmaceutical science. The development of enantioselective Strecker reactions has been the focus of increasing attention in the field of catalytic asymmetric synthesis in the past several decades. Great achievements have been made in the organocatalytic and metal-catalytic asymmetric hydrocyanation of imines. For example, many structurally new chiral metal complexes and organocatalysts were developed for use as highly efficient catalysts and led to excellent yields and enantioselectivities, the low catalytic amount of several types of developed catalysts are particularly noteworthy. The variety of catalysts also indicates a high potential for further successful Strecker reaction applications in the future. 
So far, asymmetric Strecker reactions have been mainly focused on the use of TMSCN and its in situ generated HCN as a cyanide nucleophile, one that is highly toxic and volatile. Therefore, the search for new cyanide sources, and corresponding novel imine electrophiles to accept them, has been extremely important and challenging. It is gratifying that the researchers have recently achieved some highly efficient and enantioselective catalytic Strecker reactions by successfully employing some relatively safe yet inexpensive cyanide donors such as KCN and CNCOOEt that show great potential for large scale and industrial use. On the other hand, it is very necessary for the developments of a three-component, one-pot reaction of direct access to the Strecker products starting from aldehyde or ketone, amine, and a cyanide donor, and avoided the isolation of the preformed imine leading to the desired $\alpha$-amino nitriles or acids, respectively. From an industrial point of view, the applicantion of cheap cyanide sources, such as $\mathrm{KCN}$ or $\mathrm{NaCN}$, the design of recyclable catalysts, the development for more efficient catalysts for the three-component Strecker reaction, and the exploration for further optimized reaction conditions are the research key in the future.

\section{Acknowledgements}

We thank the National Natural Science Foundation of China (21362005) and the Natural Science Foundation of the Guizhou Science and Technology Department (LKM[2011]) for financial support.

\section{References}

1. Strecker, A. Ann. Chem. Pharm. 1850, 75, 27.

http://dx.doi.org/10.1002/jlac.18500750103

2. Soloshonok, V. A.; Sorochinsky, A. E. Synthesis, 2010, 14, 2319.

http://dx.doi.org/10.1055/s-0029-1220013

3. Yet, L. Angew. Chem. Int. Ed. 2001, 40, 875.

http://dx.doi.org/10.1002/1521-3773(20010302)40:5<875::AID-ANIE875>3.0.CO;2-C

4. Gröger, H. Chem. Rev. 2003, 103, 2795.

http://dx.doi.org/10.1021/cr020038p

PMid:12914481

5. Spino, C. Angew. Chem., Int. Ed. 2004, 43, 1764.

http://dx.doi.org/10.1002/anie.200301686

PMid:15054776

6. Connon, S. J. Angew. Chem., Int. Ed. 2008, 47, 1176.

http://dx.doi.org/10.1002/anie.200703879

PMid:18175297 
7. Merino, P.; Marqués-López, E.; Tejero, T.; Herrera, R. P. Tetrahedron, 2009, 65, 1219. http://dx.doi.org/10.1016/j.tet.2008.11.020

8. Wang, J.; Liu, X. H. and Feng, X. M. Chem. Rev. 2011, 111, 6947. http://dx.doi.org/10.1021/cr200057t

PMid:21851054

9. Schmalz, H.-G.; Wirth, T. Organic Synthesis Highlights V, Wiley-VCH Verlag GmbH, Weinheim, Germany, 2008; pp 187-193.

10. Nájera, C.; Sansano, J. M. Chem. Rev. 2007, 107, 4584.

http://dx.doi.org/10.1021/cr050580o

PMid:17915933

11. Iyer, M. S.; Gigstad, K. M.; Namdev, N. D.; Lipton, M. J. Am. Chem. Soc. 1996, 118, 4910 .

http://dx.doi.org/10.1021/ja952686e

12. Ferreira, F.; Botuha, C.; Chemla, F.; Pérez-Luna, A. Chem. Soc. Rev. 2009, 38, 1162. http://dx.doi.org/10.1039/b809772k

PMid:19421587

13. Pappalardo, R. R.; Álvarez, E.; Lassaletta, J. M.; Fernández, R. Tetrahedron: Asymmetry, 2008, 19, 998 . http://dx.doi.org/10.1016/j.tetasy.2008.03.020

14. Fadel, A.; Lahrache, N. J. Org. Chem. 2007, 72, 1780.

http://dx.doi.org/10.1021/jo062382i

PMid:17256910

15. Hou, X. L.; Wu, J.; Fan, R. H.; Ding, C. H.; Luo, Z. B.; Dai, L. X. Synlett 2006, 181. http://dx.doi.org/10.1055/s-2006-926220

16. Morton, D.; Stockman, R. A. Tetrahedron, 2006, 62, 8869. http://dx.doi.org/10.1016/j.tet.2006.06.107

17. Huguenot, F.; Brigaud, T. J. Org. Chem. 2006, 71, 7075.

http://dx.doi.org/10.1021/jo0607717

PMid:16930068

18. Zhou, G.; Zheng, W.; Wang, D.; Zhang, P.; Pan, Y. Helv. Chim. Acta, 2006, 89, 520. http://dx.doi.org/10.1002/hlca.200690054

19. Harada, K. Nature, 1963, 200, 1201. http://dx.doi.org/10.1038/2001201a0

PMid:14089910

20. Gonzalez-Vera, J. A.; Garcia-Lopez, M. T.; Herranz, R. J. Org. Chem. 2005, 70, 3660. http://dx.doi.org/10.1021/jo050146m

PMid:15845004

21. Köhler, V.; Bailey, K. R.; Znabet, A.; Raftery, J.; Helliwell, M.; Turner, N. J. Angew. Chem., Int. Ed. 2010, 49, 2182. 


\section{http://dx.doi.org/10.1002/anie.200906655}

PMid:20146293

22. Kennedy, J. P.; Brogan, J. T.; Lindsley, C. W. Tetrahedron Lett. 2008, 49, 4116. http://dx.doi.org/10.1016/j.tetlet.2008.04.132

23. Merino, P.; Delso, I.; Tejero, T.; Cardona, F.; Marradi, M.; Faggi, E.; Parmeggiani, C.; Goti, A. Eur. J. Org. Chem. 2008, 2929.

http://dx.doi.org/10.1002/ejoc.200800098

24. Lu, W-Y.; Chen, P-R.; Lin, G-Q. Tetrahedron, 2008, 64, 7822.

http://dx.doi.org/10.1016/j.tet.2008.05.113

25. García, R. J. L.; Martín-Castro, A. M.; Tato, F.; Alonso, I. J. Org. Chem. 2007, 72, 5994. http://dx.doi.org/10.1021/jo0705519

PMid:17629334

26. Makino, K.; Jiang, H.; Suzuki, T.; Hamada, Y. Tetrahedron: Asymmetry, 2006, 17, 1644. http://dx.doi.org/10.1016/j.tetasy.2006.06.004

27. Bernardi, L.; Bonini, B. F.; Capitö, E.; Comes-Franchini, M.; Dessole, G.; Fini, F.; Fochi, M.; Herrera, R. P.; Ricci, A. Eur. J. Org. Chem. 2006, 207. http://dx.doi.org/10.1002/ejoc.200500501

28. Badorrey, R.; Cativiela, C.; Díaz-de-Villegas, M. D.; Díez, R.; Galbiati, F.; Gálvez, J. A. J. Org. Chem. 2005, 70, 10102.

http://dx.doi.org/10.1021/jo051592c

PMid:16292847

29. Tan, L.; Yasuda, N.; Yoshikawa, N.; Hartner, F. W.; Eng, K. K.; Leonard, W. R.; Tsay, F. R.; Volante, R. P.; Tillyer, R. D. J. Org. Chem. 2005, 70, 8027.

http://dx.doi.org/10.1021/jo0511187

PMid:16277324

30. García, R. J. L.; García, M. C.; Navarro, A. L.; Tato, F.; Martín-Castro, A. M. Arkivoc, 2005, (vi), 33.

31. Wang, X-J.; Zhang, F.; Liu, J-T. Tetrahedron, 2008, 64, 1731. http://dx.doi.org/10.1016/j.tet.2007.12.002

32. Simon, J.; Nguyen, T. T.; Chelain, E.; Lensen, N.; Pytkowicz, J.; Chaume, G.; Brigaud, T. Tetrahedron: Asymmetry, 2011, 22, 309. http://dx.doi.org/10.1016/j.tetasy.2011.01.007

33. Barnwell, N.; Watts, A.; Purdie, L.; Gill, D. M. Tetrahedron Lett. 2012, 53, 1951. http://dx.doi.org/10.1016/j.tetlet.2012.02.008

34. Yuan, X-M.; Xu, J.; Liu, Z-J.; Yang, X-J. Wang, L-M.; Zhang, Y.; Yang, X-Y.; He, X-P.; Liu, J-T. J. Fluorine Chem. 2012, 144, 102. http://dx.doi.org/10.1016/i.jfluchem.2012.07.017

35. Midura, W. H.; Krysiak, J.; Rzewnicka, A.; Supeł, A.; Łyżwa, P.; Ewas, A. M. Tetrahedron 2013, 69, 730. http://dx.doi.org/10.1016/j.tet.2012.10.085 
36. Pori, M.; Gallett, P.; Soldati, R.; Giacomini, D. Eur. J. Org. Chem. 2013, 1683. http://dx.doi.org/10.1002/ejoc.201201533

37. Barbero, M.; Cadamuro, S.; Dughera, S.; Ghigo, G. Org. Biomol. Chem. 2012, 10, 4058. http://dx.doi.org/10.1039/c2ob25584g

PMid:22527016

38. Tanaka, K.; Shiraishi, R. Green Chem. 2000, 2, 272. http://dx.doi.org/10.1039/b006424f

39. Evans, G. J. S.; White, K.; Platts, J. A.; Tomkinson, N. C. O. Org. Biomol. Chem. 2006, 4, 2616.

http://dx.doi.org/10.1039/b602645a

PMid:16791326

40. Schmid, M. B.; Zeitler, K.; Gschwind, R. M. J. Am. Chem. Soc. 2011, 133, 7065. http://dx.doi.org/10.1021/ja111544b

PMid:21500780

41. Sigman, M. S.; Jacobsen, E. N. J. Am. Chem. Soc. 1998, 120, 5315.

http://dx.doi.org/10.1021/ja980299+

42. Abell, J. P.; Yamamoto, H. J. Am. Chem. Soc. 2009, 131, 15118.

http://dx.doi.org/10.1021/ja907268g

PMid:19799383

43. Kaur, P.; Pindi, S.; Wever, W.; Rajale, T.; Li G. G. Chem. Commun. 2010, 46, 4330. http://dx.doi.org/10.1039/c0cc00287a

PMid:20464009

44. Kaur, P.; Pindi, S.; Wever, W.; Rajale, T.; Li G. G. J. Org. Chem. 2010, 75, 5144. http://dx.doi.org/10.1021/jo100865q

PMid:20597482 PMCid:PMC2912979

45. Kaur, P.; Wever, W.; Pindi, S.; Milles, R.; Gu, P.; Shi, M.; Li, G. G. Green Chem. 2011,13, 1288 .

http://dx.doi.org/10.1039/c1gc15029d

46. Gou, S. H.; Huang, X.; Liu, X. H.; Feng, X. M.; Wang, J.; Hu, X. L.; Jiang, J. Angew. Chem. Int. Ed. 2007, 46, 8468.

http://dx.doi.org/10.1002/anie.200703188

PMid:17768752

47. Wünnemann, S.; Fröhlich, R.; Hoppe, D. Eur. J. Org. Chem. 2008, 684.

http://dx.doi.org/10.1002/ejoc.200700763

48. Belokoñ, Y. N.; Hunt, J.; North, M. Tetrahedron: Asymmetry, 2008, 19, 2804.

49. Banphavichit, V.; Mansawat, W.; Bhanthumnavin, W.; Vilaivan, T. Tetrahedron 2009, 65, 5849.

http://dx.doi.org/10.1016/j.tet.2009.04.098

50. Ramalingam, B.; Seayad, A. M.; Li, C; Garland, M.; Yoshinag, K.; Wadamoto, M.; Nagata, T.; Chai, C. L. L. Adv. Synth. Catal. 2010, 352, 2153. 


\section{http://dx.doi.org/10.1002/adsc.201000462}

51. Takamura, M.; Hamashima, Y.; Usuda, H.; Kanai, M.; Shibasaki, M. Angew. Chem. Int. Ed. 2000, 39, 1650.

http://dx.doi.org/10.1002/(SICI)1521-3773(20000502)39:9<1650::AID-

ANIE1650>3.0.CO;2-P

52. Kato, N.; Suzuki, M.; Kanai, M.; Shibasaki, M. Tetrahedron Lett. 2004, 45, 3153.

http://dx.doi.org/10.1016/j.tetlet.2004.02.077

53. Ishitani, H.; Komiyama, S.; Hasegawa, Y.; Kobayashi, S. J. Am. Chem. Soc. 2000, 122, 762.

\section{http://dx.doi.org/10.1021/ja9935207}

54. Chavarot, M.; Byrne, J. J.; Chavant, P. Y.; Vallee, Y. Tetrahedron: Asymmetry 2001, 12, 1147.

\section{http://dx.doi.org/10.1016/S0957-4166(01)00144-6}

55. Masumoto, S.; Usuda, H.; Suzuki, M.; Kanai, M.; Shibasaki, M. J. Am. Chem. Soc. 2003, $125,5634$.

http://dx.doi.org/10.1021/ja034980+

PMid:12733893

56. Hatano, M.; Hattori,Y.; Furuya,Y.; Ishihara, K. Org. Lett. 2009, 11, 2321.

http://dx.doi.org/10.1021/o1900680f

PMid:19405538

57. Karimi, B. and Maleki, A. Chem. Commun. 2009, 45, 5180.

http://dx.doi.org/10.1039/b908854g

PMid:20448986

58. Karimi, B.; Maleki, A.; Elhamifar, D.; Clark, J. H. and Hunt, A. J. S. Chem. Commun. 2010, 46, 6947.

http://dx.doi.org/10.1039/c0cc01426e

PMid:20730158

59. Achard, T. R. J.; Clutterbuck, L. A.; North, M. Synlett 2005, 1828.

60. Blacker, J.; Clutterbuck, L. A.; Crampton, M. R.; Grosjean, C.; North, M. Tetrahedron: Asymmetry 2006, 17, 1449.

http://dx.doi.org/10.1016/i.tetasy.2006.05.015

61. Khan, N. H. ; Saravanan, S.; Kureshy, R. I.; Abdi, S. H. R.; Sadhukhan, A.; Bajaj, H. C. J. Organometal. Chem. 2010, 695, 1133.

http://dx.doi.org/10.1016/j.jorganchem.2010.01.018

62. Esteves, M. A.; Gigante, B.; Santos, C.; Guerreiro, A. M.; Baleizão, C. Catal. Today 2013, $218-219,65$.

http://dx.doi.org/10.1016/j.cattod.2013.06.022

63. Ohkuma, T.; Nobuhito, K. Synlett 2012, 23, 1865.

http://dx.doi.org/10.1055/s-0032-1316545

64. Uemura, M.; Kurono, N.; Ohkuma, T. Org. Lett. 2012, 14, 882. 


\section{http://dx.doi.org/10.1021/ol203408w}

PMid:22260419

65. Sakai, T.; Soeta, T.; Endo, K.; Fujinami, S.; Ukaji, Y. Org. Lett. 2013, 15, 2422.

http://dx.doi.org/10.1021/ol400898p

PMid:23646983

66. Ishitani, H.; Komiyama, S.; Kobayashi, S. Angew. Chem. Int. Ed. 1998, 37, 3186.

http://dx.doi.org/10.1002/(SICI)1521-3773(19981204)37:22<3186::AID-

ANIE3186>3.0.CO;2-E

67. Grossmann, A.; Enders, D. Angew. Chem. Int. Ed. 2012, 51, 314.

http://dx.doi.org/10.1002/anie.201105415

PMid:22121084

68. Grondal, C.; Jeanty, M.; Enders, D. Nat. Chem. 2010, 2, 167.

http://dx.doi.org/10.1038/nchem.539

PMid:21124474

69. Reingruber, R.; Baumann, T.; Dahmen S.; Bräse, S. Adv. Synth. Catal. 2009, 351, 1019. http://dx.doi.org/10.1002/adsc.200800798

70. Sadhukhan, A.; Saravanan, S.; Khan, N. H.; Kureshy, R. I.; Abdi, S. H. R.; Bajaj, H. C. J. Org. Chem. 2012, 77, 7076.

http://dx.doi.org/10.1021/jo300642z

PMid:22834772

71. Maruoka, K.; Ooi, T. Chem. Rev. 2003, 103, 3013.

http://dx.doi.org/10.1021/cr020020e

PMid:12914490

72. Ooi. T. Asymmetric Synthesis and Application of $\alpha$-Amino Acids. Chapter 11, ACS Symposium Series, American Chemical Society, Washington, D.C., 2009, Vol. 1009, pp $177-189$.

73. Ooi, T.; Uematsu, Y.; Maruoka, K. J. Am. Chem. Soc. 2006, 128, 2548.

http://dx.doi.org/10.1021/ja058066n

PMid:16492034

74. Ooi, T.; Uematsu, Y.; Fujimoto, J.; Fukumoto, K. Maruoka, K. Tetrahedron Lett. 2007, 48, 1337.

http://dx.doi.org/10.1016/j.tetlet.2006.12.122

75. Yan, H. L. Oh, J. S.; Lee, J. -W.; Song, C. E. Nat. Commun. 2012, 3, 1212.

http://dx.doi.org/10.1038/ncomms2216

PMid:23169053

76. Xi, Y. M.; Shi, X. D. Chem. Commun. 2013, 49, 8583.

http://dx.doi.org/10.1039/c3cc40825f

PMid:23948716

77. Berkessel, A.; Cleemann, F.; Mukherjee, S.; Müller, T. N.; Lex, J. Angew. Chem. Int. Ed. 2005, 44, 807. 


\section{http://dx.doi.org/10.1002/anie.200461442}

PMid:15657971

78. Liu, Y-L.; Shi, T-D.; Zhou, F.; Zhao, X-L.; Wang, X.; Zhou, J. Org Lett. 2011, 13, 15, 3826.

79. Pan, S. C.; List, B. Org. Lett. 2007, 9, 1149.

http://dx.doi.org/10.1021/o10702674

PMid:17319677

80. Zhang, F-G.; Zhu, X-Y.; Li, S.; Nie, J.; Ma, J-A. Chem. Commun. 2012, 48, 11552.

http://dx.doi.org/10.1039/c2cc36307k

PMid:23090241

81. Shao, Y-D.; Tian, S-K. Chem. Commun. 2012, 48, 4899.

http://dx.doi.org/10.1039/c2cc31001e

PMid:22499398

82. Liu, Y-L.; Zhou, J. Chem. Commun. 2013, 49, 4421.

http://dx.doi.org/10.1039/c2cc36665g

PMid:23090050

83. Li, N-K.; Liu, Z-M.; Huang, X-F.; Zhang, J-X.; Chen, X.; Wang, Y.; Wang, X-W. RSC Adv. 2013, 3, 9154.

http://dx.doi.org/10.1039/c3ra41640b

84. Wang, D.; Liang, J. Y.; Feng, J. C.; Wang, K. R.; Sun, Q. T. Zhao, L.; Li, D.; Yan, W. J.; Wang, R. Adv. Synth. Catal. 2013, 355, 548.

85. Wang, J.; Wang, W.; Li, W.; Hu, X.; Shen, K.; Tan, C.; Liu, X.; Feng, X. Chem. Eur. J. 2009, 15, 11642.

$\underline{\text { http://dx.doi.org/10.1002/chem.200900936 }}$

PMid:19774566

86. Wen, Y. H.; Xiong, Y.; Chang, L.; Huang, J. L.; Liu, X. H.; Feng, X. M. J. Org. Chem. 2007, 72, 7715 .

$\underline{\text { http://dx.doi.org/10.1021/jo701307f }}$

PMid:17727295

87. Wen, Y. H.; Gao, B.; Fu, Y. Z.; Dong, S. X.; Liu, X. H.; Feng, X. M. Chem. Eur. J. 2008, $14,6789$.

$\underline{\text { http://dx.doi.org/10.1002/chem.200800319 }}$

PMid:18551491

88. Saravanan, S.; Sadhukhan, A.; Khan, N. H.; Kureshy, R. I.; Abdi, S. H. R.; Bajaj, H. C. J. Org. Chem. 2012, 77, 4375.

http://dx.doi.org/10.1021/jo300349f

PMid:22497557

89. Zhang, G-W.; Zheng, D-H.; Nie, J.; Wang, T.; Ma, J-A. Org. Biomol. Chem. 2010, 8, 1399. http://dx.doi.org/10.1039/b924272d

PMid:20204214 
90. Hashimoto, T.; Kimura, H.; Maruoka, K. Tetrahedron: Asymmetry 2010, 21, 1187. http://dx.doi.org/10.1016/j.tetasy.2010.04.067

\section{Authors' Biographies}

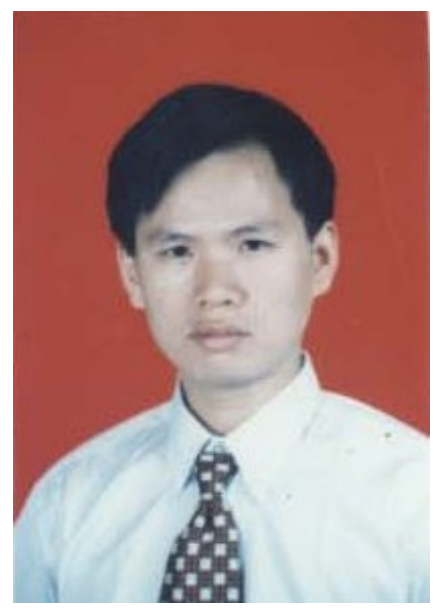

Xiao-hua Cai was born in 1966. He graduated at Shaoyang Technology University, China, in 1988. He received his M.S. in chemistry from Xi'an Modern Chemistry Research Institute in 1999, and his Ph.D. in sciences from Graduate School of the Chinese Academy of Sciences in 2005. He became a professor at College of Chemistry and environmental Science, Guizhou Minzu University in 2006, His research interests are in the fields of organic reactions, drug molecular design, and bioactivity of natural products.

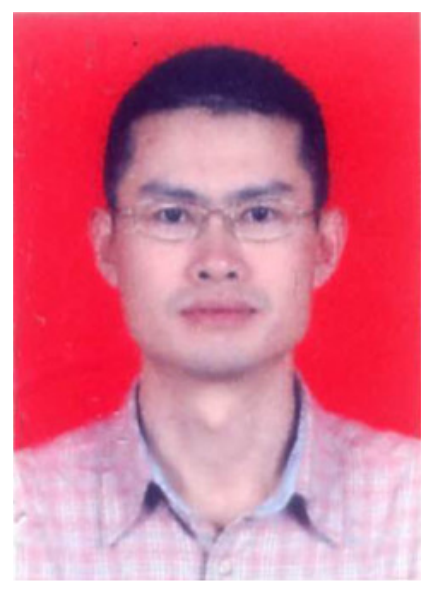

Bing Xie was born in 1963. He is a senior professor of Guizhou Minzu University, Guiyang. He graduated from Southwest Normal University, China, in 1985. He received his M.S. in chemistry from Guizhou University 2006. His research interests are focused on the synthesis of heterocyclic compounds which may have prospective biological and pharmaceutical activities. 